\title{
Embryo-endosperm interactions
}

Nicolas M. Doll1, $2^{*}$ and Gwyneth C. Ingram $3^{3^{*}}$

1 Department of Plant Biotechnology and Bioinformatics, Ghent University, Ghent, Belgium.

2 VIB Center of Plant Systems Biology, Ghent, Belgium.

3Laboratoire Reproduction et Développement des Plantes, ENS de Lyon, CNRS, INRAE, F-69342, Lyon, France.

${ }^{*}$ Authors for correspondence

Nicolas.Doll@psb.vib-ugent.be; Gwyneth.Ingram@ens-lyon.fr 


\begin{abstract}
In Angiosperms, double fertilization triggers the concomitant development of two closely juxtaposed tissues; the embryo and the endosperm. Successful seed development and germination requires constant interactions between these tissues, which occur across their common interface. The embryo-endosperm interface is a complex, and poorly understood compound apoplast, comprising components derived from both the embryo and endosperm, across which nutrients transit to fuel embryo development. Interface properties, which affect molecular diffusion and thus communication, are themselves dynamically regulated by molecular and physical dialogues between the embryo and endosperm. Here we review current understanding of embryo-endosperm interactions, with a particular focus on the structure, the properties and the function of their shared interface. Concentrating on Arabidopsis, but with reference to other species, we aim to situate recent findings within the broader context of seed physiology, developmental biology, and genetic factors such as parental conflicts over resource allocation.
\end{abstract}

\title{
KEY WORDS: EMBRYO, ENDOSPERM, SEED, COMMUNICATION, APOPLAST, DEVELOPMENT
}

\section{INTRODUCTION}

The production of seeds, which ensure the protection, nourishment and dispersal of the main product of sexual reproduction -the embryo- by the maternal tissues, undoubtedly made a major contribution to the remarkable evolutionary success of seed plants, which currently dominate most terrestrial ecosystems. From the great diversity found in the fossil record, only 5 lineages of seed plants currently remain, four are gymnosperm lineages, and the fifth contains the angiosperms. In extant and extinct gymnosperms and probably in the common ancestor of angiosperms and gymnosperms, the nutritive tissues surrounding the developing embryo are formed directly by the haploid female megagametophyte (107). Gymnosperm megagametophytes can be large and may contain several archegonia, each of which harbors a fertilization -competent egg cell, allowing polyembryony in some species.

One of the major innovations that sets apart the angiosperm lineage from gymnosperms, was the acquisition of fertilization competence in a second cell of the much reduced female gametophyte. 
This innovation underlies double fertilization. During this process, the two sperm cells carried within the pollen grain, which are haploid mitotic siblings, fuse with the haploid egg cell and a second fertilization competent cell (the central cell usually di-haploid) of the female gametophyte. These fusion events trigger the concomitant proliferation of two distinct fertilization products, the embryo and the endosperm, respectively. These two fertilization products develop enveloped within the maternal seed coat (testa) in most angiosperm species (117) (94).

The exact train of events leading to the acquisition of double fertilization is a subject of considerable discussion (133). However, its consequence was to tether the proliferation of the major nutritive tissue within the seed, the endosperm, to egg cell fertilization. The evolutionary advantages of this dramatic developmental switch, have been widely discussed $(5,61,132)$ and are not the subject of this review. However, the introduction of a male genome into the endosperm, a major site of nutrient flux between the mother plant and the developing embryo, is thought to have exacerbated genomic conflicts over resource allocation, which in turn may have contributed to the rapid radiation of the angiosperms $(35,69,101,102,132)$. Double fertilization has thus changed the nature of seed development, making the angiosperm seed a much more complex structure in which three distinct organisms, with differing genetic compositions, cohabit and develop concomitantly in a limited space. The coordination in the development of these three organisms is crucial to produce viable seeds and requires a precise and complex dialog, especially between the two fertilization products, which will form the focus of this review.

A first step in the comprehension of the embryo endosperm interaction was the characterization of the developmental events happening throughout embryo and endosperm development. Multiple highly detailed and beautifully illustrated monographs dating back over more than 10 decades have described the development of both tissues in numerous angiosperm species $(4,79,111)$. However, these analyses rely on fixed and sectioned plant materials and provide little dynamic insight into developmental communication. In reality, although indispensable for seed development, the seed coat and associated tissues significantly impede the in vivo observation and manipulation of the embryo and endosperm in most species, explaining why most of our current knowledge regarding the molecular regulation of endosperm-embryo communication is derived from studies in the model plant species Arabidopsis thaliana. Arabidopsis, in addition to providing unparalleled genetic resources, also produces numerous small seeds, with a simple structure and reproducible developmental trajectory. However, it is important to bear in mind that Arabidopsis seed development has distinct characteristics, which are not necessarily shared with other angiosperm species. The physical and molecular interactions between the embryo and endosperm appear, for example, to differ profoundly between the Brassicaceae (exemplified by Arabidopsis), the grasses (exemplified by maize) and the legumes (such as peas). Furthermore, these model species likely represent only a fraction of the mechanistic diversity in embryo-endosperm interactions across the Angiosperms. In discussing the mechanistic and functional basis of embryo-endosperm interactions, 
we will, therefore concentrate on recent findings in Arabidopsis, whilst using these as a basis for a broader reflection on the possible divergence of communication mechanisms.

Understanding the complex interactions between the embryo and the endosperm organisms requires a vision of the evolutionary origin of extant processes that it is difficult to obtain. Their current interactions result from a long evolutionary history that integrated different parameters such as environment pressure, parental conflicts or, in agronomically important species, the human selection of specific attributes (such as size, or content of specific metabolites). It is within this complex evolutionary context and in the light of recent and novel findings that this review aims to discuss the nature and consequences of embryo endosperm communication.

\section{Double fertilization: changing communication pathways.}

\subsection{The Egg cell and central cell before fertilization: two connected gametes.}

In Arabidopsis, the embryo and endosperm are derived from the fertilization of the egg cell and the di-haploid central cell respectively. Both the egg cell and the central cell originate from the cellularization of the multinucleate female gametophyte coenocyte. From its inception, the egg cell shares a common interface with the central cell at its chalazal pole. In some species, hooks and ingrowths increase the size of this interface, suggesting a necessity for extensive apoplastic exchanges (75). In numerous angiosperm species, the cell wall between the egg cell and the central cell has been described as discontinuous giving rise to large areas in which the plasma-membranes of the egg and central cell are apparently directly juxtaposed, potentially facilitating gamete fusion $(75,119,136)$. In Arabidopsis however, the cell wall between the egg and central cell has been reported to be continuous but of irregular thickness and with deep furrows (160). The apoplastic composition of this interface remains a mystery. However, it is perforated by plasmodesmata that connect the egg and central cell cytoplasms $(39,82,145)$. This symplastic connection has been experimentally demonstrated by the injection of molecular tracers into the central cell of the embryo sac-apparent species Torenia fournieri Lind., and more recently in Arabidopsis. $(50,71,151)$. Although the diffusion limits of these connections are variable they allow, for instance, the movement of small RNAs produced by the central cell, which maintain the repression of egg cell transposable elements by promoting methylation $(50,76)$.

Based on these findings, it seems probable that the egg and the central cell can communicate through both symplastic and apoplastic channels. Symplastic communication is essential for the maturation of both cells and is a prerequisite for the normal development of the endosperm and the embryo $(166,173)$. Assessing the requirement for apoplastic communication at this stage of development is more complex, both due to the presence of symplastic communication, and a lack of informative mutants. 


\subsection{Post-fertilization symplastic isolation of the embryo and endosperm.}

Egg cell fertilization is associated with a rapid change at the embryo endosperm interface. In vitro studies of isolated maize egg cells showed a rapid extrusion of material within 30 s after fertilization. This material forms a continuous wall within the following 20 minutes (99). Callose was found in the newly formed cell wall of the zygote in several Ericaceae species (171), suggesting that the rapidly exocytosed material could be callose. Rapid extrusion of material may prevent the fusion of more than one sperm cell with the egg cell, but also isolates the newly formed sporophyte from the surrounding endosperm and the degenerating synergids.

Studies in both Arabidopsis and Torenia fournieri Lind. embryo sacs showed symplastic movement of molecules between the endosperm and the embryo is strongly reduced or even absent after fertilization (Figure 1), suggesting a restriction or rupture in symplastic communication $(50,71)$. This symplastic isolation requires either a removal or a blocking of the pre-existing plasmodesmata. In Arabidopsis, plasmodesmata between the embryo and the endosperm disappear after fertilization (113). Later in development, the embryo appears to remain symplastically isolated from the endosperm as demonstrated by the absence of cytoplasmic GFP diffusion toward the endosperm (150). Consistent with this, no reports of the presence of plasmodesmata at the embryonic surface in Arabidopsis are present in the literature. Together these observations suggest that, in these species at least, the embryo and endosperm become symplastically isolated soon after fertilization.

The presence of symplastic barriers between the embryo and endosperm is variable. Intriguingly in some Fabaceae species and several Crassulaceae species, the presence of plasmodesmata at the embryo-endosperm interface has been reported after fertilization. These are, however, restricted to the basal cell of the two-celled embryo and later to the suspensor $(47,84,95$, 96, 140). Microinjection of tracers into the basal suspensor cell of Sepium acre (Crassulaceae) revealed unidirectional symplastic movement from the basal suspensor cell towards the endosperm. Unlike the situation in Arabidopsis, movement from the embryo proper towards the basal suspensor cell was not detected, indicating that, the suspensor may be symplastically isolated in species where symplastic connections are maintained between the endosperm and suspensor (172). This idea is further supported by the results of elegant feeding experiments in $P$. coccineus and $P$. vulgaris, which show that although sucrose movement from the endosperm to the suspensor (which in these species could either be apoplastic or symplastic, due to the presence of plasmodesmata) is passive, movement from the suspensor into the embryo proper requires energy, suggesting that this movement occurs against an endogenous concentration gradient and is likely apoplastic in nature (183). 


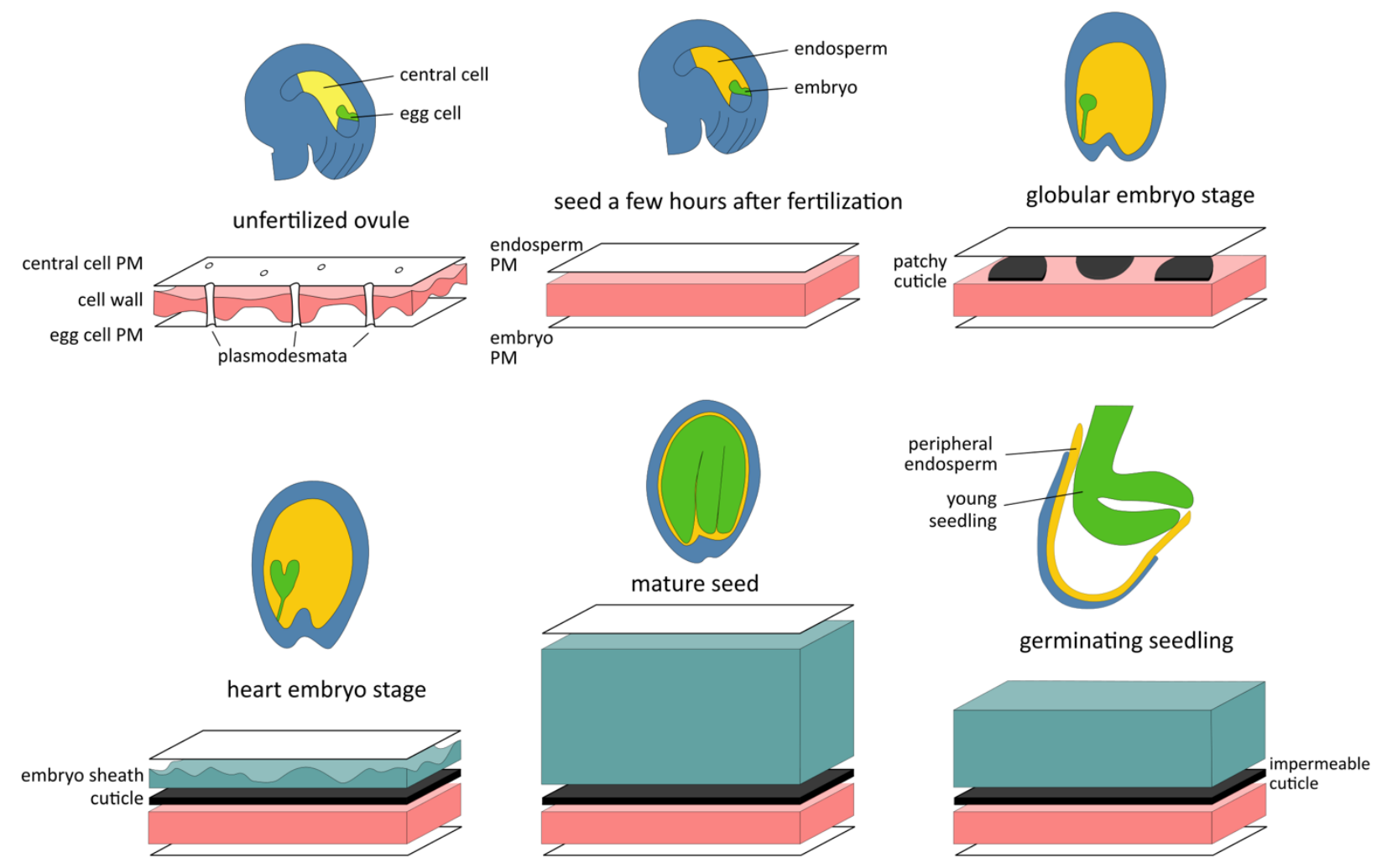

Figure 1: Structure of the embryo endosperm apoplast at different stages during seed development in Arabidopsis. In an unfertilized ovule, the central cell and the egg cell are separated by an irregular cell wall perforated by plasmodesmata. After double fertilization, a rapid secretion of cell wall material thickens the cell wall between the embryo and endosperm (pink). From the early globular stage onwards, the embryonic cuticle (black) is secreted by the embryo, first in a patchy pattern, before forming a continuous and thin layer. Material produced by the endosperm cells is secreted at the embryo-endosperm interface and accumulates on the outer face of the embryo cuticle to form the embryo sheath (blue-green). After germination, a continuous layer of embryo sheath remains on the cotyledon and hypocotyl surfaces, while the cuticle is remodeled to form the impermeable seedling cuticle. $\mathrm{PM}=$ plasma membrane.

In conclusion, double fertilization strongly influences how the egg cell/embryo and central cell/endosperm can communicate. In some species, symplastic communication between the embryo and the endosperm is maintained in the suspensor, but in these species, symplastic communication between the embryo proper and the suspensor may be blocked or strongly reduced. No evidence of post-fertilization symplastic communication (either direct, or indirect (via the suspensor)) between embryo proper and endosperm appears to exist, suggesting that apoplastic communication likely plays a major role in embryo development.

\section{Apoplastic movement between the embryo and endosperm}

\subsection{Molecules involved in embryo endosperm communication.}


The tight coordination of embryo and endosperm development implies an extensive dialogue throughout seed development. Although deciphering the whole picture will likely remain a challenge for decades, some pieces of the puzzle have already been discovered. For example, signalling peptides have been found to diffuse across the embryo-endosperm apoplast to mediate communication between these tissues during seed development. These include the ESF peptides secreted by the central cell and then by the endosperm after fertilization, which promote suspensor elongation via the activation of WOX8 expression (30). A further example involves the TWISTED SEED1 peptide $(44,57)$, which will be discussed in more detail in the following section.

Hormonal communication is also thought to occur between the two tissues. Research has been mainly focused on auxin, a key factor necessary for the patterning of early embryo development in Arabidopsis (62). Although the apical-basal polarization of the early embryo depends upon a basal (suspensor) - apical (embryo-proper) auxin flux, the origin of the auxin involved in this early patterning event is enigmatic. A recent study provided evidence that maternal tissues (the integuments) produce auxin that can be imported across the interface between the basal cell of the embryo and the integuments (134). Auxin also plays a key a role in the initiation of endosperm development by stimulating nuclear division, $(6,53)$ and the export of endosperm-derived auxin coordinates the post-fertilization development of the endosperm with that of surrounding maternal tissues (the integuments) $(53,55)$. If, as proposed, auxin biosynthesis in the integuments is necessary for the establishment of embryo polarity (134), it follows that endosperm-derived auxin produced post fertilization, which in turn stimulates auxin production in the seed coat (52), could, at least indirectly, be implicated in early embryo patterning. In support of this, Arabidopsis plants lacking the auxin biosynthetic enzymes YUCCA1 (YUC1), YUC4, YUC10, and YUC11 show embryo defects, whereas the yuc1 yuc4 double mutant shows no abnormal phenotype. Because YUC10 and YUC11 are expressed specifically in the endosperm, Figueiredo and Köhler proposed that the embryo phenotype is caused by a lack of auxin production in the endosperm (55). However, whether auxin -and other hormones- diffuses directly through the embryo endosperm apoplast in Arabidopsis is still debated and the exact contribution of the endosperm auxin to the embryo development remains to be clarified.

In maize, the situation is slightly different, as auxin responses, measured by the activity of the DR5 reporter, are absent from the embryo until the transition stage ( 7DAP). At this point, DR5 signals appear at the top of the embryo. Strong DR5 signal in the surrounding endosperm, suggests that auxin may be directly exported from the endosperm to the embryo (25), where its redistribution may be involved in the establishment of the apical-basal axis $(42,58,59)$. Furthermore, an endosperm auxin maximum has been proposed to orient embryonic growth (25). Functional studies of appropriate auxin defective mutants are however needed to test these hypotheses. 
Throughout its development, the embryo requires nutrients such as carbohydrates, amino acids and ions to support its development. In addition, many angiosperm species store significant quantities of nutrients in the embryo that can be remobilized and used during seedling establishment. Although the embryos of some species appear to be capable of limited photosynthetic activity $(2,15$, $135,147)$, the vast majority of nutrients used and stored by embryos are imported from maternal tissues, making seeds major energy and nutrient sinks $(1,158)$.

Once released into the integument apoplast the exact pathway taken by nutrients to reach the embryo is unclear, but two main possibilities exist. One possible route involves direct maternalembryo transport at the apoplastic interface that links the base of the suspensor to the maternal apoplast. Suspensors vary dramatically in size among species and although the suspensor-maternal interface is limited to one cell in Arabidopsis, giant bulbous suspensors found in some legumes or members of the Crassulaceae permeate maternal tissues in an almost parasite-like manner (95, $111,182)$. In both giant and small suspensors, transcriptomic analysis has revealed an enrichment in the expression of genes associated with transport and carbohydrate metabolic processes, highlighting a universal role as a nutrient highway (27). Although in species with semi-persistent giant suspensors, significant quantities of nutrients are likely to be directly absorbed from maternal tissues by the embryo (97), in most species, including Arabidopsis and maize, the suspensor path is not sufficient to fully supply the embryo, especially during later stages of development, after suspensor degeneration, and when the demands of the embryo are greatest. Therefore, nutrient transfer between the maternal tissues and the embryo necessarily involves exchanges across the embryo-proper endosperm interface.

The second path consequently involves trans-endosperm transport, implying the uptake of sugars by the endosperm at the interface between the endosperm and the integuments, their diffusion across the endosperm, and their subsequent export from the endosperm and uptake by the embryo (120). The endosperms of the vast majority of Angiosperms go through an initial phase of mitotic nuclear divisions in the absence of cytokinesis, leading to the formation of a multinucleate coenocyte (127). It seems likely that during this stage, nutrients are imported into the endosperm cytoplasm from maternal tissues, and then re-exported to the embryo surface by transmembrane transporters (Figure 2). This is supported by the observation that the sucrose exporter SUC5, expressed in the coenocytic endosperm, is necessary for early embryo expansion (7). In addition the fact that mutants with reduced suspensor length tend to show a delay in early embryo development (3) could suggest that the surface area of the early embryo in contact with the coenocytic endosperm determines nutrient uptake capacity, at least in Arabidopsis. Subsequent cellularization of the endosperm dramatically changes the nature of trans-endosperm molecular movement, by creating apoplastic bridges between maternal tissues and the embryo that bypass the endosperm cytoplasm, and will be discussed further in section 4. 
Deciphering the exact pathways taken by sugars, amino acids and other nutrients into the early embryo will necessitate detailed studies of transporter localizations and activities within the endosperm suspensor and embryo. This represents a significant technical challenge due to the internal position of the tissues of interest.
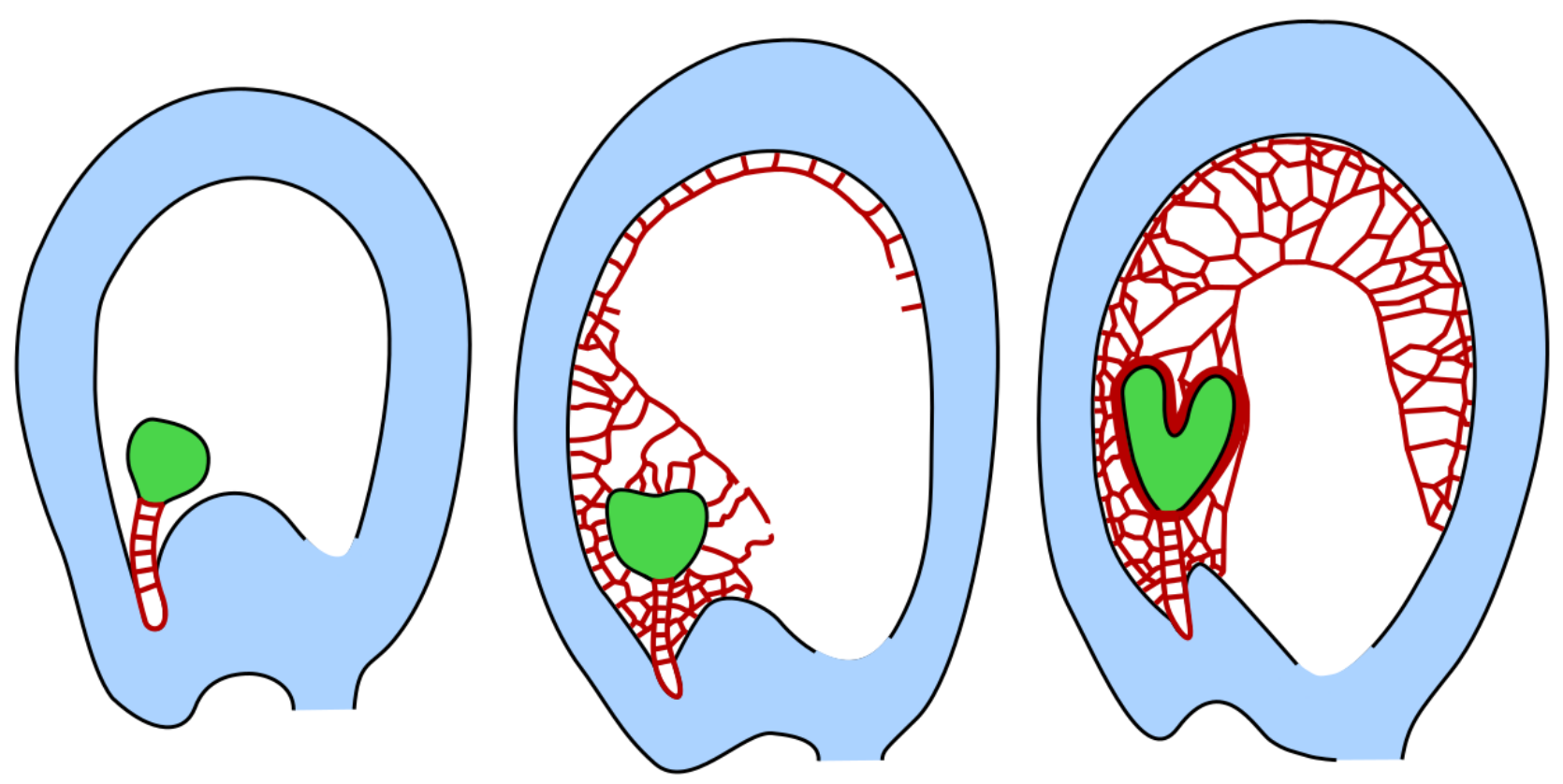

Embryo proper apoplastic domain

Seed coat apoplastic domain

_ Cell walls form apoplastic bridges between maternal tissues and embryo proper

_ Cuticles potentially selectively limiting apoplastic diffusion

Figure 2: Endosperm cellularization generates apoplastic bridges connecting the embryo proper to the seed coat apoplastic domains in Arabidopsis. In the young seed, before endosperm cellularization, the only apoplastic interface between the maternal tissues and the embryo proper is the suspensor. Endosperm cellularization increases the number of apoplastic junctions connecting the maternal tissues with the embryo proper. From the heart stage onwards, the embryo endosperm apoplastic space is further modified by endosperm deposits forming the nascent embryo sheath. Cuticles that could potentially selectively limit the movement of some molecules are indicated in black.

\section{The control of molecular diffusion across the embryo-endosperm interface.}

\subsection{The genesis of the embryonic cuticle.}


During early embryonic development, the outermost cell layer of the embryo proper differentiates into a protoderm, which subsequently gives rise to the epidermis (83). Plant epidermal cells are highly polar and form a continuous cell layer that can be developmentally modified to optimize plant interactions with the surrounding environment. This is also true of the embryonic epidermis, which covers the embryo proper, and which is modified during embryogenesis to support embryo development and viability.

One of the major characteristics of epidermal cells is their ability to secrete unesterified hydroxy fatty acids which become polymerized on the outer surface of the epidermal cell wall, together with other molecules, in order to form a continuous film called the cuticle $(80,181)$. The secretion of cuticular components and their transport through the epidermal cell wall is highly polar and, because epidermal cells propagate through anticlinal cell divisions, once the cuticle has been established, it is continuously "inherited", forming a scaffold that can be extended and reinforced as tissues expand. However, during early embryogenesis no cuticle exists on the surface either of the suspensor or the embryo proper and the embryonic cuticle must form de novo $(31,37)$. In Arabidopsis, osmophilic patches start to become apparent at the embryo proper-endosperm interface at the globular stage of embryogenesis (Figures 1 and 3). These patches may be a consequence of the secretion of "cutinosomes" (vesicles containing cuticle components) which have been reported to traverse the outer epidermal cell wall of the embryo before depositing their contents (153). These patches rapidly coalesce and form a continuous cuticle by the late-globular/early heart stage of embryogenesis (31, 154) (Figures 1 and 3). Genes encoding key enzymes known to be involved in cuticle biosynthesis, are expressed in the embryo epidermal cells (31). However how cuticle components become condensed into a polymerized and continuous film at the embryo endosperm-interface remains a mystery. Although the suspensor is devoid of cuticle, a recent study showed that the root tip is also surrounded by a thin cuticle layer, albeit with differing properties from that covering the rest of the embryo, indicating that after the suspensor degenerates at the torpedo stage, the whole embryo is encapsulated by a continuous cuticular membrane $(9,89)$.

Over the past few decades, the analysis of mutants involved in embryonic cuticle formation has allowed the identification of many genes involved in embryonic cuticle establishment. These genes have been extensively studied in Arabidopsis and can be classified in three categories (Figure 3). Firstly, genes implicated in epidermis specification like the ATML1 and PDF2 transcription factors the ARABIDOPSIS CRINKLY4 and ABNORMAL LEAF SHAPE2 Receptor Like Kinases (RLKs) and the CALPAIN DEK1 $(112,138,157,168)$. Since cuticle production is a unique characteristic of epidermal cells, affecting the specification of this cell type necessarily impacts cuticle formation. The second class of genes encodes proteins involved in the biosynthesis of the embryonic cuticle and expressed in the epidermis (likely under the direct or indirect control of proteins involved in epidermal specification). Despite the extensive literature on post-embryonic cuticle biosynthesis and the fact 
that many genes known to be involved in the biosynthesis of functional cuticles post embryogenesis are expressed in the embryo epidermis from the globular stage onwards (31), few single mutants have shown convincing embryonic phenotypes. However, a recent study identified FAB2, AAD5, and $A A D 1$, three enzymes involved in the desaturation of fatty acids, as being involved in the production of a functional embryonic cuticle $(90,181)$ (Figure 3).

A third class of genes is involved in the control of embryonic cuticle integrity. Loss of function of these genes does not directly affect either epidermis specification or cuticle biosynthesis. However in mutants, the embryonic cuticle remains discontinuous and uncondensed even at late developmental stages $(31,138)$ suggesting a loss of the ability to perceive and repair cuticle gaps. A recent study has shown that these genes are involved in bidirectional embryo-endosperm communication required to achieve cuticle integrity monitoring (45). In the endosperm a subtilase (serine protease) called ABNORMAL LEAF SHAPE1(ALE1) is produced around the embryo. ALE1 expression depends on the activity of an endosperm specific bHLH transcription factor-complex comprising ZHOUPI (ZOU) and ICE1 $(38,156,174,180)$. In the embryo, the two redundant Leucine Rich Repeat RLKs (LRR-RLKs) GASSHO1/SHENGEN3 (GSO1) and GSO2 are produced in the embryonic epidermis where they localize in a non-polar fashion in the epidermal cell membrane (57, 162). The final pathway component, TWISTED SEED1 (TWS1) (57) is the precursor of a sulfated peptide. Inactive sulfated proTWS1 peptides are secreted by the embryo into its apoplast. If the embryonic cuticle is discontinuous, proTWS1 can escape to the endosperm where they are activated by proteolytic removal of a C-terminal inhibitory domain by ALE1. The active peptides then diffuse back into the embryo, bind the GSO1 and GSO2 receptors on the embryonic surface, and trigger a cellular response leading to cuticle gap filling. Once the cuticle is continuous, ALE1 and proTWS1 are physically separated and signaling stops. New gaps appearing during embryonic growth can be repaired by this pathway as pathway components remain expressed until embryo growth arrests (44) (Figure 3).

The establishment of a functional embryonic cuticle is of critical importance in the mature embryo, since cuticle integrity prevents catastrophic water loss from the seedling upon germination. However, the cuticle integrity pathway that has just been described is active at the globular embryo stage in Arabidopsis. Why does the embryo need to establish a functional embryonic cuticle so early in seed development? And what are the consequences in terms of embryo-endosperm interactions?

\subsection{The embryonic cuticle: A filter or a barrier?}

That the embryo cuticle restricts the apoplastic movement of peptides is demonstrated by the very mechanism that leads to integrity establishment. Interestingly, a potential function in restricting peptide movement had previously been proposed based on the synergistic genetic interactions of mutants affected in cuticle integrity, and mutants with compromised epidermal identity, which led to 
the proposition that the presence of cuticle defects could lead to the inappropriate leakage of developmentally important ligands from the embryo $(123,138)$. Although the identity of the ligands involved remains an enigma, the cuticle could thus ensure the stability of embryonic patterning and/or cell differentiation.

However, even if developmentally important, it seems possible that early cuticle formation could impede other processes, including nutrient uptake from the surrounding endosperm, possibly explaining why the suspensor is not covered in cuticular material. However, in Arabidopsis the suspensor degenerates long before nutrient uptake and storage in the embryonic tissues is complete, or even maximal. Additionally, the small suspensor would rapidly become insufficient to explain the observed nutrient flow into the embryo. In Arabidopsis, analysis of embryonic cuticle permeability to Toluidine Blue, a small hydrophilic dye, revealed that although embryonic surface permeability decreases throughout embryogenesis in wild type plants, it still remains relatively high in comparison to that of post-germination organs, with dye penetrating in a matter of minutes even in fully expanded embryos $(9,31,34)$. Furthermore, although the root pole of the embryo has been shown to be covered by a structurally intact cuticle, it is considerably more permeable to Toluidine Blue than the cuticle present on other areas of the embryo $(9,31)$. Given these observations, it appears unlikely that the embryonic cuticle would represent a significant barrier to metabolites such as sugars and amino acids, which are of roughly comparable molecular weight to Toluidine blue. Although nutrient influx might be higher at the root pole, this represents a very small surface area, and the expression of transporters throughout the embryonic epidermis suggests that nutrients can transit over the entire embryonic surface, at least in Arabidopsis (170). Thus, the embryonic cuticle of Arabidopsis at least, probably acts more as a filter than as a hermetic barrier.

Although an intact cuticle covering the entire embryonic surface is necessary for the survival of epigeal plants upon germination, the properties, and even the existence of this apoplastic filter can vary dramatically between species and even between organs. For instance in cereals, the embryonic axis (hypocotyl and coleoptile) is surrounded by a thick, and very impermeable cuticle $(46,66,100)$ while the scutellum is highly permeable despite reports of the presence of a cuticle-like structure on the scutellum surface $(29,164)$. This difference could be related to the function of the scutellum surface, which facilitates endosperm nutrient uptake both during embryogenesis and during germination, and never emerges from the seed coat or becomes a photosynthetic organ. Similarly, in Vicia faba and in pea, in which cotyledons actively uptake sugars and amino acids during seed development $(159,170)$ but again do not emerge from the seed coat during germination, the cotyledon epidermis differentiates transfer cell-like properties but does not produce a clearly defined cuticular layer (16-18). 


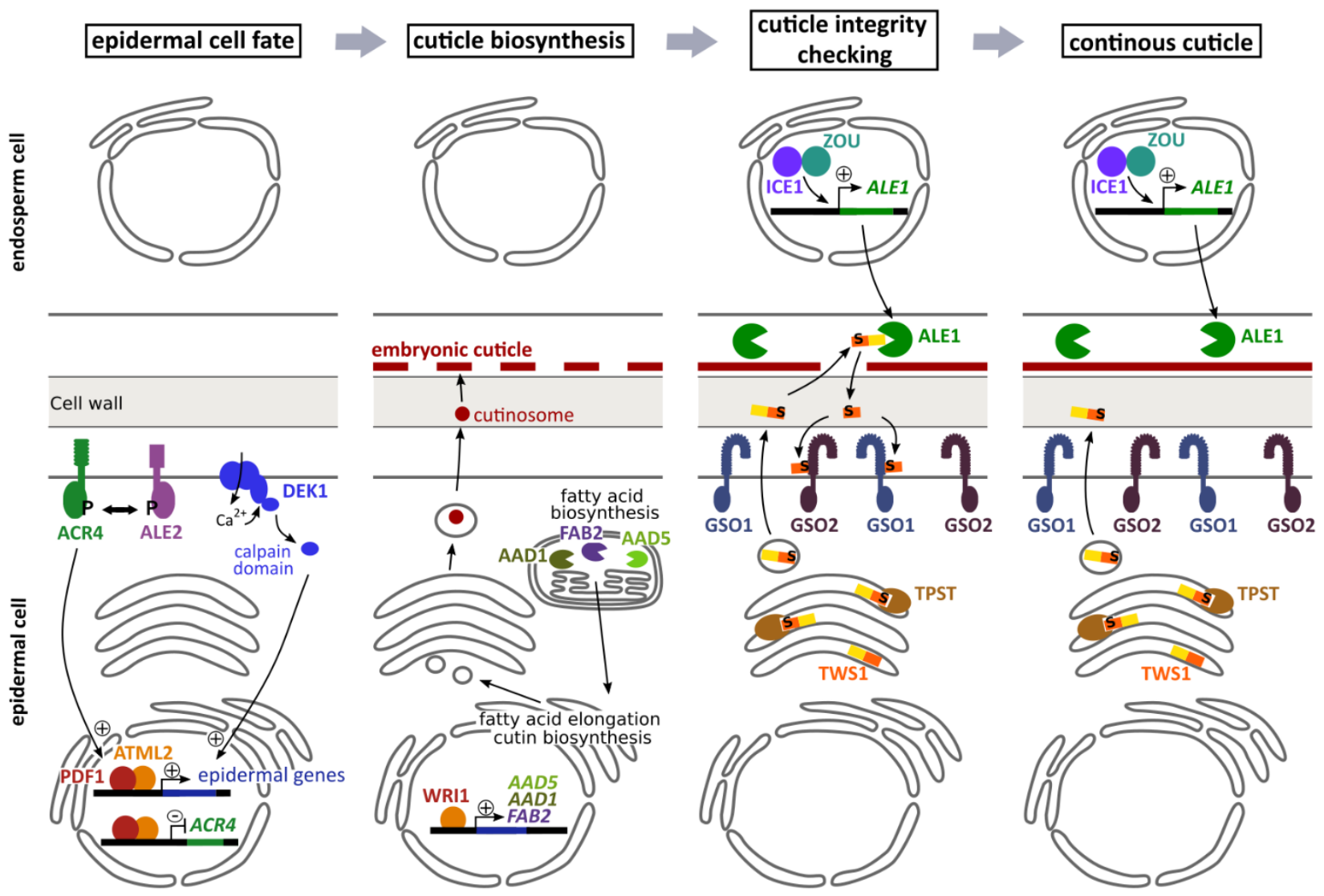

Figure 3: The different steps required for the embryonic cuticle formation in Arabidopsis. For each step, the main molecular actors and their corresponding pathways are represented. As a first step, the most external cell layer of the embryo proper differentiates into an epidermis. Then, the epidermal cells start to produce cuticle components that are secreted into the apoplast to form a discontinuous "patchy" cuticle. A bidirectional exchange of signals between the embryo and the endosperm allows the detection of the gaps in this structure, mediates their closure, and thus ensures cuticle integrity. After the completion of cuticle gap closure, the pathway is shut down unless new gaps appear during embryo expansion.

\section{Endosperm cellularization: The embryo takes the upper hand.}

Endosperm cellularization is a poorly understood process that involves the partitioning of the nuclei, cytoplasm and vacuole of the endosperm coenocyte into individual uninucleate cells. Early endosperm development involves nuclear divisions in the absence of cytokinesis, leading to the formation of a single polynucleate coenocyte with a large central vacuole $(21,127,149)$. In Arabidopsis cellularization generally initiates when the embryo is at the early heart stage of development, at around the time when rapid embryo growth, and early reserve accumulation initiate. Cellularization has been proposed to play a critical role in embryo development, because in Arabidopsis mutants in which the endosperm fails to cellularize, the embryo generally arrests at the heart stage, leading to seed abortion (73). In addition, the regulation of the initiation of endosperm cellularization appears to be a key target of parental imprinting, being retarded by the paternal 
genome and promoted by the maternal genome, supporting the idea that cellularisation, at least in Arabidopsis, could significantly affect resource allocation to the developing embryo $(50,65,98,101$, $102,141)$.

\subsection{Endosperm cellularization around the embryo: Bridging the gap.}

In many species, including Arabidopsis, endosperm cellularization initiates in the micropylar region, in which a densely cytoplasmic endosperm fully envelopes the developing embryo. Beautiful work by Otegui and Staehelin suggests that a process involving the progressive genesis of "syncytialtype" cell plates that form progressively from the midplane between both sister and non-sister nuclei, occurs (129). Such plates can then fuse with the endosperm and embryo cell wall, effectively forming direct links between these two apoplastic spaces. This observation is consistent with work from other species, suggesting that cell walls directly link the endosperm and embryo surface, even in species where the endosperm is considered to be "non cellularized" such as pea (114). Whether these links reflect the presence of individual cells, or simply localized cell wall connections, remains to be resolved through the application of 3-dimensional imaging techniques. Nonetheless, these connections may play important roles in ensuring embryo nutrition. Two mechanisms are generally evoked. The first being that apoplastic connections anchor the embryo in a zone of the endosperm where nutrient transfer from maternal tissues (presumably via the endosperm) is optimized, for example close to areas of maternal export (proposed in some legumes, where the maternal cell wall differentiate transfer cell-like characteristics) (114). The second proposed mechanism is that by forming physical "bridges" directly linking the maternal apoplast to the embryonic apoplast, endosperm cellularization effectively extends the direct apoplastic interface between the maternal and embryonic apoplast, permitting the embryo to "bypass" the endosperm and absorb nutrients directly from maternal tissues (Hehenberger et al., 2012). (figure 2)

\subsection{The regulation of Endosperm Cellularization.}

Endosperm cellularization, as evoked above, has been shown to be promoted by the maternal genome and retarded by the male genome. The FERTILIZATION INDEPENDENT SEED POLYCOMB REPRESSIVE COMPLEX2 (FIS PRC2) acts in the female gametophyte to repress seed development in the absence of fertilization, and subsequently acts maternally in the endosperm to promote cell cycle arrest and cellularization $(53,68,73,91,92,108)$. As a result, in seeds arising from female gametophytes lacking a functional FIS PCR2, the endosperm fails to cellularize, and the embryo arrests at the heart stage of development. One of the key targets of PRC2, with respect to the regulation of endosperm cellularization, is the MADS-box transcription factor AGAMOUS-LIKE 
62 (AGL62), which acts to repress endosperm cellularization (86). Loss of AGL62 function leads to seed lethality associated with extremely early endosperm cellularization, which is proposed to be an indirect consequence of seed coat expansion failure (52). Loss of function of the maternally encoded FIS PRC2 complex leads to a convincing partial rescue of the ag/62 endosperm cellularization defect, and restores seed viability (73).

Another key factor regulating endosperm cellularization is the plant hormone auxin. Interploidy crosses with an excess of paternal genomes, which show similar cellularization defects to those observed in seeds lacking maternal FIS PRC2, show increased and prolonged auxin production in the endosperm (6). Furthermore, increasing auxin production in the endosperm leads to delayed cellularization, whilst during normal seed development, cellularization occurs only once auxin levels in the endosperm have dropped. Auxin appears to act either parallel to, or downstream of, proteins such as AGL62, itself a regulator of auxin transport (52), to regulate cellularization (6). A recent study in rice has shown not only that OsYUC11 is necessary for endosperm development, but that, as is the case for the Arabidopsis YUC10 gene $(54,74)$, OsYUC11 is expressed predominantly from the male genome during early seed development (176).

Finally, although endosperm cellularization has been proposed to require mitosis(21, 149), it also appears to be linked with a cessation of nuclear proliferation. Whilst endosperms lacking maternal FIS PRC2, like those with a paternal genome excess, undergo excess nuclear proliferation (67) and fail to cellularize, mutants with reduced proliferation, such as those defective in the poorly understood signaling pathway involving the proteins HAIKU1 (IKU1), IKU2 and MINISEED3/WRKY10, cellularize earlier than wild-type seeds $(64,109,167)$.

\section{Invading the endosperm.}

\subsection{Embryo invasion of the endosperm and cell elimination.}

In most angiosperm species, the embryo grows invasively into the surrounding endosperm. To allow embryo expansion, the endosperm is remodeled and progressively eliminated (115). In Arabidopsis, most of the endosperm is removed by a lytic process. At maturity, only the peripheral endosperm layer remains intact and alive. This lytic cell death is suppressed in both ice1 and zou mutants, which harbor a persistent endosperm in addition to their cuticle phenotype $(93,180)$. ZOU is specifically expressed in the endosperm while its partner, ICE1, is extensively expressed both within and outside the seed $(28,38,85,104)$. A constitutively active ICE1 protein enhances endosperm degradation $(38,60)$, but contrary to other cell death regulating transcription factors, neither ICE1 nor ZOU can directly trigger programmed cell death in the tissues where they are overexpressed $(28,32,63,85$, 180). This suggests that they act upstream of cell execution "setting the scene". In zou mutants, 
cell wall thinning and cell separation observed in the endosperm of wild-type seeds do not occur. Consistent with this, many cell wall remodelers usually expressed in the endosperm, are not expressed in zou mutants $(60,169)$. Thus ZOU may regulate endosperm cell wall softening, which in turn allows invasive embryo growth, a hypothesis that has been backed up by biophysical analysis of zou mutant seeds (60). In mutants where embryo growth arrests very early, endosperm cells do eventually die but the cell content is not cleared $(60,175)$.

In plant species with a so called "persistent" or "semi persistent" endosperm, embryo invasion remains limited to a sub-domain of the endosperm. In cereals, most of the endosperm persists at maturity. However, as in Arabidopsis, only the peripheral layer, called the aleurone, remains alive (137). The central starchy endosperm undergoes a programmed cell death that preserves the cell corpses but the contribution of the embryo to this process appears minimal. However, around the embryo, two developmentally and cytologically distinct zones of endosperm cell elimination can be distinguished. The first is the "Embryo Surrounding Region" (ESR), a small patch of densely cytoplasmic cells surrounding the young embryo, and proposed to have both nutrient transfer and developmental roles $(42,66,128)$. The embryo rapidly outgrows this zone and invades the bulk endosperm above. The ESR is eliminated at around 14 DAP in wild-type plants, and ESR elimination correlates with that of the embryonic suspensor, suggesting that the two processes may be linked (66). The elimination of the ESR depends on the activity of the maize ZHOUPI orthologue ZmZOU (also known as Opaque11) $(51,66)$. Once the embryo has emerged from the ESR cell death can be observed around the expanding scutellum, in a zone called the Endosperm Associated with Scutellum (EAS) (Figure 4). Interestingly this process does not involve the complete removal of cell corpses as seen in the ESR, and cell wall remnants persist at the embryo/endosperm interface $(43,66,142)$. ZmZOU/O11 does not appear to be involved in either EAS elimination or, indeed, starchy endosperm PCD. To what extent the elimination of the ESR or of the EAS depend upon embryo growth is not clear.

\subsection{Endosperm elimination and the formation and function of the embryo/endosperm interface.}

Why is the endosperm in the maize EAS not fully degraded? One possibility relates to the fact that, unlike the situation in Arabidopsis, where cotyledon cuticle integrity is a requirement for seedling survival upon germination, in maize the scutellum remains enclosed within the seed upon germination. As a result, the maize scutellum, like the cotyledons of hypogeal dicotyledonous species such as pea, does not suffer from the antagonistic requirements of forming an apoplastic barrier whilst acting as a major conduit for nutrient exchange. Indeed, the presence of functional apoplastic barriers of the surface of these structures remains unproven. Nonetheless, the lack of such a barrier could also render the developing embryo susceptible to attack from lytic enzymes 
involved in endosperm elimination, possibly providing an explanation for the lack of complete cell wall breakdown in the EAS of the maize endosperm.

Surprisingly, the idea that endosperm breakdown is required to release nutrients to the developing embryo, or indeed to facilitate nutrient transport from maternal tissues to the developing embryo during development, although widely assumed, has not been rigorously tested or demonstrated. The expression of membrane localized transporters in the endosperm surrounding the developing embryo does however suggest that this is the case $(26,43,124)$. For instance, the sugar exporters SWEET 11 and 15, which are required for normal seed filling in Arabidopsis, are expressed in the embryo surrounding region of Arabidopsis endosperm $(7,26)$. The route for other nutrients toward the embryo is still poorly understood in Arabidopsis, but may resemble that of sugars. In Arabidopsis, AtCAT6, UMAMIT 25 and 28 have been shown to be expressed in the late endosperm but their early expression and exact contribution to embryo filling remains to be clarified $(10,70,124)$. In maize, both amino acid transporters and SWEETs are strongly expressed in the EAS (43). Other endosperm-expressed transporters may transfer various other nutrients toward the embryo, such as biotin (via SUC5) in Arabidopsis (131), and iron (via ZmYSL2) in maize (184).

\subsection{Endosperm-derived materials contribute to the building of the embryo sheath in Arabidopsis.}

As highlighted above, in Arabidopsis, the bulk endosperm is completely degraded. Nonetheless, some materials derived from the endosperm accumulate around the embryo, and contribute to its surface structure and function. Notably, the embryo sheath is progressively build up outside the embryonic cuticle. The embryo sheath has an organized and homogeneous structure with a regular thickness, suggesting that its formation involves active assembly on the embryo surface (Figure 1). The embryo sheath is strongly and specifically recognized by anti-EXTENSIN antibodies and has thus been proposed to include a 3D EXTENSIN-based scaffold $(41,121)$. EXTENSINS can selfassemble in vitro through isodityrosine crosslinking $(22,103)$. EXTENSIN epitopes are first detectable immunologically at the mid-late heart stage of embryogenesis, when endosperm breakdown initiates (121). They initially localize within vesicles in the endosperm cells surrounding the embryo and are secreted to the apoplast before accumulating at the embryo surface. The secretion of sheath materials may precede endosperm degeneration, with progressive glycosylation subsequently rendering them detectable by specific antibodies. However, the lack of sheath production in zou mutants supports a link between endosperm degradation and embryo-sheath formation (121). At maturity, the embryo sheath forms a thick envelope around the embryo and is very tightly associated with the embryo surface (Figure1, and Figure 4).

\subsection{The function of the embryo sheath.}


Identification of the Kerberos (krs) mutant, which is defective in embryo sheath formation, has allowed a deeper understanding of the function of this structure in Arabidopsis. KRS is a cysteinerich peptide specifically produced in the endosperm surrounding the embryo from the heart stage onwards. The expression of KRS is fully dependent upon ZOU function (121). However, unlike zou mutants, krs mutants show no defects in endosperm elimination. Furthermore, genetic analysis suggests that $K R S$ acts in a pathway that is parallel to the cuticle integrity pathway. In krs mutants the sheath (as detected by anti-EXTENSIN antibodies) is completely absent, and physical separation between the growing embryo and the endosperm does not occur (121). Abnormal embryo endosperm adhesion during development leads to mis-orientation of embryo growth in some seeds. After germination, seed coat shedding from the cotyledons (Figure 1) is also impaired (41). The observed adhesion between the embryo and endosperm, both before and during germination suggest that the embryo sheath acts as an anti-adhesive structure. Consistent with this, the adhesion of germinating cotyledon surfaces to silica beads measured by Atomic Force Microscopy is considerably stronger in $k r s$ mutants than in the wild type (41).
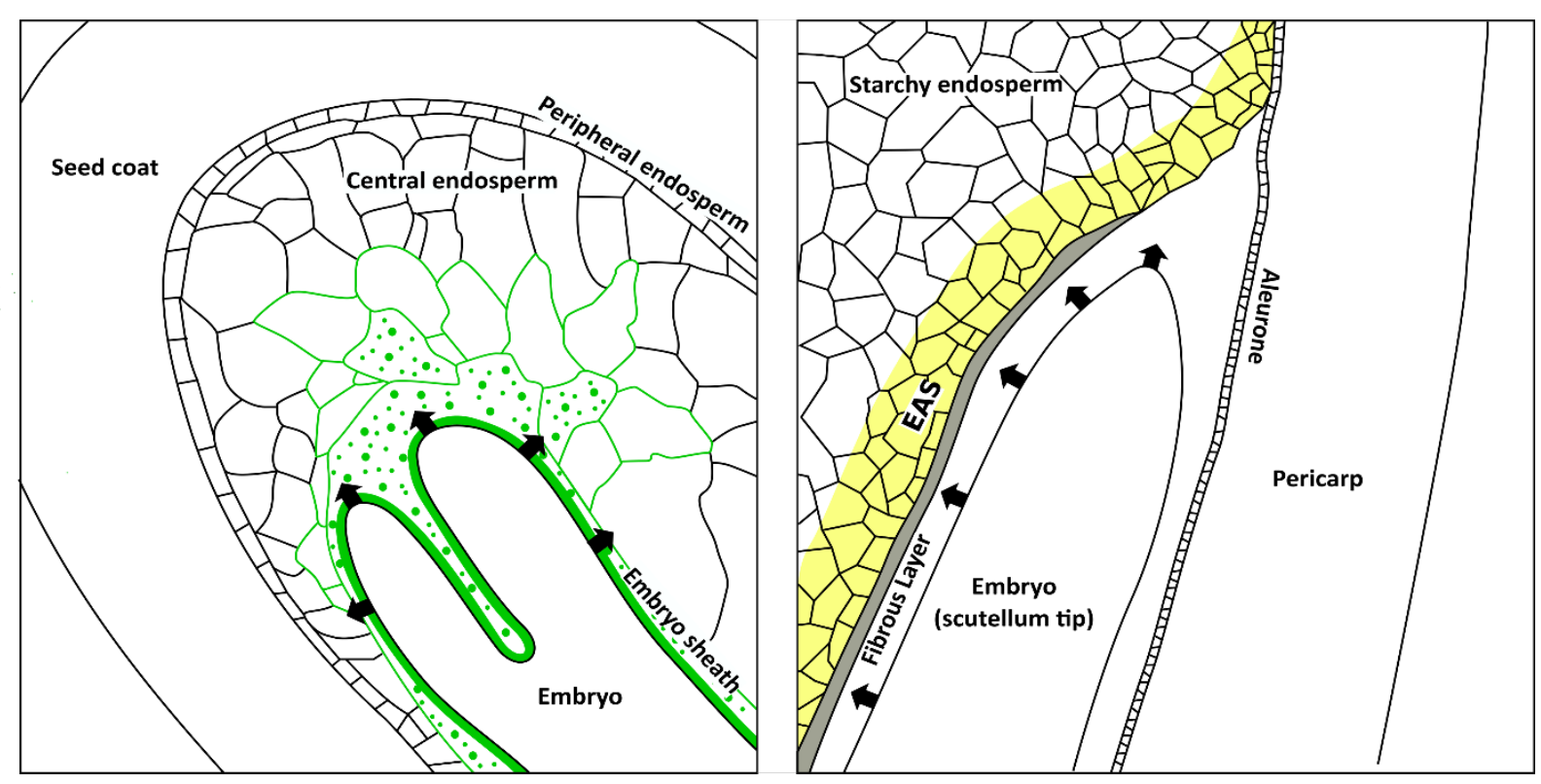

Figure 4: Embryo invasion of the endosperm in Arabidopsis (left panel) and in maize (right panel). In Arabidopsis, embryo invasion leads to an almost complete removal of the central endosperm cells. Prior to embryo invasion, components rich in epitopes specifically detected by anti-EXTENSIN antibodies (indicated in green) are specifically produced by endosperm cells surrounding the embryo and deposited at the embryo endosperm interface to form the embryo sheath, which subsequently mediates the physical separation of the embryo and endosperm. In maize, embryo invasion leads to a crushing of endosperm cells, leaving undigested wall that accumulate in a fibrous layer. In a limited number of endosperm cell layers adjacent to the scutellum (EAS, in yellow), the embryo partially regulates the expression of a specific transcriptomic network. Arrows indicate the direction of embryo expansion 
Understanding of the mechanism of sheath formation, biochemical composition, and deposition remains rudimentary. However, although the formation of EXTENSIN epitopes in the embryo surrounding endosperm of Arabidopsis occurs normally in mutants lacking cuticle integrity pathway components, the deposition of a structured embryo sheath on the embryo surface is fully dependent upon this pathway, and is lost both in ale1 and in gso1 gso2 double mutants (121). This suggests that an embryo-derived factor, acting downstream of GSO signaling, could be implicated in sheath deposition on the embryonic surface, complexifying further the dialogue between the embryo and the endosperm necessary for embryonic surface formation.

Does the sheath exist in other species? The presence of a "hyaline layer" around the embryos of Brassicaceae species suggests that this structure is conserved throughout this family (165). In pea, an embryo "sheath" has been described around the developing embryo (114), although its origins remains unclear. More distantly, in the black nightshade (solanum nigrum), material from limited endosperm breakdown in the "zone of separation and secretion" has been reported to form a thick, fibrous structure around the embryo. This structure could have a similar function to the Arabidopsis embryo sheath in separating the embryo and endosperm (19, 20). Finally, in castor bean, where endosperm cells die on the cotyledon surface after germination, a "slimy" layer of crushed cells has been proposed to facilitate the separation of the two tissues (144).

To sum up, the invasion of the endosperm by the embryo is often accompanied by interface modifications involving components of the dying endosperm, which may participate in the physical separation of the two structures. How these modifications affect embryo-endosperm communication, remains to be investigated. However, the physical detachment of the two tissues could be important for extending the apoplastic space between the embryo and the endosperm, facilitating nutrient circulation and uptake. However, very little is known regarding the diffusion properties of these interfaces, and this role remains speculative at best.

\section{6..The final act: Endosperm embryo communication and germination.}

Embryo endosperm communication does not end at seed maturity. In many angiosperm seeds part of the endosperm remains alive during seed quiescence, and plays critical roles in the germination process. Recent studies suggest that these roles involve complex physical and metabolic interactions with the embryo as well as hormone and peptide-mediated communication.

\subsection{The role of the endosperm in controlling seed dormancy.}

The endosperm is critical in maintaining seed dormancy. This role has been extensively reviewed, including in this volume (81) and we will therefore provide only a relatively brief overview. 
Seed dormancy is a complex concept, and covers a range of phenomena affecting the ability of a seed to germinate despite favorable environmental conditions $(24,56)$. Arabidopsis seeds show a shallow primary seed dormancy that is established during seed development, and progressively lost post shedding, increasing the potential of seeds to respond to environmental conditions favorable for germination. It has been described as the culmination of the seed maturation process. In Arabidopsis the importance of the endosperm in maintaining seed dormancy has been shown through both genetic studies, and though dissection studies in which the embryo and endosperm are separated and then physically reunited ("bedding assays") (reviewed in $(24,56)$ ). The fact that the endosperm-specific ZOU transcription factor is critical in determining the depth of primary dormancy reinforces this view (110). Interestingly, in legumes, many of which do not contain a persistent endosperm layer, dormancy is physical rather than physiological, and mediated by the impermeable seed coat $(13,56)$.

Bedding assays provide a powerful tool with which to dissect tissue communication during germination and have led to a convincing model in which endosperm derived Abscisic Acid (ABA), produced at high levels in dormant imbibed seeds, mediates embryo dormancy maintenance (34, 106) (Figure 5). Transporters potentially involved in the export of $A B A$ from the endosperm and its import into the embryo have been identified (87). Endosperm-mediated ABA production is stimulated by the DELLA protein RGL2. In non-dormant seeds, RGL2 is degraded via a GA- and embryodependent process, suggesting retrograde communication. Dormancy has been proposed to prevent GA dependent RGL2 degradation, through a lack of production of GA signalling components (12, 106).

Although several potential GA transporters have been shown to be expressed during germination and to affect seed germination $(33,88,155)$, conclusive evidence that the origin of the GA perceived in the endosperm during Arabidopsis seed germination is embryonic remains sparse, since GA biosynthesis can also occur in the endosperm $(125,130,177)$. Other embryo-derived signals, including mechanical signals (see below) could also be involved in coordinating germination $(116,139)$. In cereals a role for embryo-derived GA in controlling endosperm behavior, including amylase secretion by the aleurone and subsequent cell death during seed germination, has also been proposed (11). Consistent with this, both amylase production and cell death progress from the embryo containing zone to more distant zones of the endosperm. In Ricinus, where endosperm remains on the cotyledons after germination, cell death initiates proximally to the embryo before expanding outwards (144), again suggesting that the embryo promotes endosperm cell death, although the signal involved is unclear.

In Arabidopsis, the proposed movement of hormones between the endosperm and embryo raises an important question. How, if the embryo already has an intact cuticle, do these hormones traverse the embryo-endosperm interface? As evoked previously, the cuticle of the mature embryo, although physically intact remains relatively permeable to hydrophilic molecules which may explain, 
in part this exchange $(9,31)$. In addition, a recent study showed that changes in embryo cuticle structure and composition that render it less permeable, occur during the early stages of germination. These changes depend upon the presence of the endosperm, and are mediated by the production of sulfated peptides including the TWS1-related CIF1 and CIF2 peptides (potentially perceived by the GSO1 and GSO2 receptors) as well as the PSY1 peptide (potentially perceived by the PSY1 RECEPTOR (PSY1R). This impermeabilization is proposed to render the embryo less sensitive to endosperm-derived ABA, thus decreasing endosperm-imposed germination inhibition. Consistent with this, germinating wild-type embryos rapidly lose their ABA sensitivity, whilst it is retained in embryos defective in cuticle biosynthesis. Nonetheless it is important to note that tws 1 mutants closely resemble gso1 gso2 double mutants (44), suggesting that the proposed GSO1/GSO2 dependent roles of CIF1 and CIF2 during germination are not sufficient to rescue strong defects in embryonic cuticle development generated prior to seed maturation. However, this recent work clearly shows that peptide-mediated communication between the endosperm and the embryo could play an important role in maintaining the integrity of the embryonic cuticle during the germination of wild-type seeds.

\subsection{Mechanical communication between the embryo and the endosperm during germination.}

In addition to peptide and hormonal cross-talk, mechanical interactions between the embryo and endosperm have long been proposed to play important roles in the regulation of seed germination. In several species endosperm softening and cell expansion, culminating in endosperm rupture, allow the growth of the embryonic root during the germination process. The mechanical properties of the micropylar endosperm are a key target for regulation. Specific cell wall modifications, either mediated enzymatically or through the production of Reactive Oxygen Species occur specifically in this region $(48,49,105,152,185)$. Furthermore, genotypes in which the composition of the endosperm is altered due to the loss of function of specific enzymes (such as alterations in xyloglucan metabolism, pectin methylesterification status, mannan breakdown or the loss of expression of parietal proteins such as EXPANSINS) affect germination $(77,78,143,146,148,178)$

Are changes in hormone production (such as GA production) and the expression of cell wall modifying enzymes in the micropylar endosperm dependent upon the growth of the embryo? Several studies have suggested that this might be the case $(23,36,78,116)$. A detailed transcriptome analysis of different seed compartments during Arabidopsis germination showed that, in support of the idea that a mechanical cue induced by expansion of the embryo axis could be perceived in the endosperm, touch-induced genes are strongly upregulated in the endosperm prior to radical emergence (36). Analysis of the expression of cell wall modifying genes such as that encoding the EXPANSIN AtEXP2, support the hypothesis that embryo expansion is a key factor in triggering GA- 
dependent gene expression in the endosperm, that in turn modifies the physical properties of this tissue (139)

\subsection{The importance of the endosperm in seedling establishment.}

In addition to regulating seed germination, the endosperm has also been shown to promote seedling establishment post germination (Figure 5). Part of this role may reflect the importance of the endosperm as a nutrient storage compartment, from which nutrients are remobilized upon germination to fuel seedling growth until full autotrophy is established. Even seeds in which the endosperm is almost entirely degraded, such as Arabidopsis, store nutrients in residual endosperm that are remobilized and taken up by the embryo in the form of sugars and amino acids upon germination $(118,130,161)$. As evoked above nutrient mobilization in the endosperm requires hormonal, and potentially mechanical dialogues between the embryo and endosperm that have been extensively reviewed (for example $(23,179)$ and will not be discussed further here due to space constraints. Interestingly however, recent studies have highlighted other roles for the endosperm in ensuring seedling establishment. Very recent work (34) has shown that the endosperm is a critical factor in ensuring a successful embryo-seedling transition, including both normal photomorophogenic and skotomorphogenic development, and that in the absence of endospermderived cues, both primary root development and seedling chloroplast development are seriously compromised. These defects appear not to be caused by a lack of endosperm-derived nutrients, suggesting that other signals are involved. Interestingly similar defects in seedling establishment have been reported in the germinating seeds of mutants unable to produce or perceive GA, suggesting that, again, the endosperm-derived signal could be GA dependent (72).

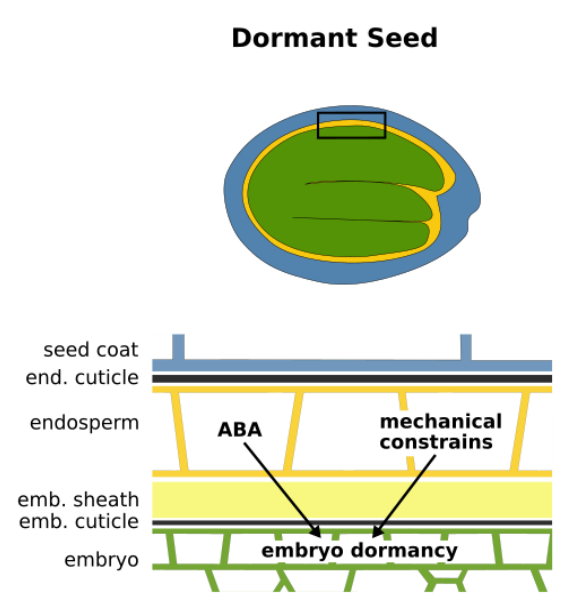

Imbibition and germination

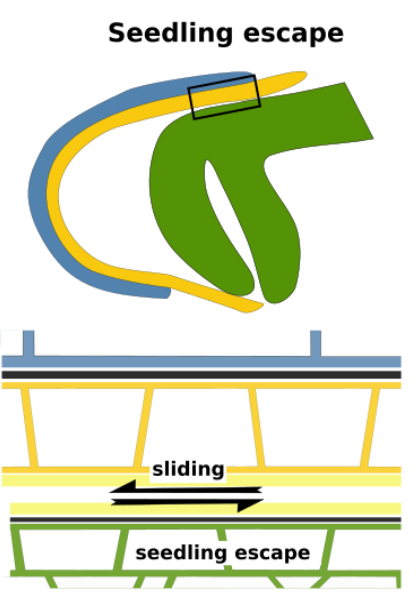

Figure 5: Embryo endosperm dialogue during germination and seedling establishment in

Arabidopsis. In dormant seeds (left panel) both mechanical constrains and chemical cues (especially abscisic acid $(A B A)$ ) from the endosperm maintain embryo dormancy. During imbibition and germination (central panel), 
the embryo triggers peripheral endosperm vacuolization and thus remobilization of nutrients in a GA dependent fashion. Together with other unknown endosperm derived factors, this process promotes seedling establishment. Sulfated peptides from the endosperm regulate cuticle remodeling, increasing cuticle impermeability. At the root tip, the embryo triggers GA-dependent endosperm cell wall remodeling, allowing thus root tip emergence. Finally, during seedling escape (right panel), the endosperm derived embryo sheath, through its anti-adhesive properties facilitates seedling emergence.

Defects in seedling establishment have also been observed in mutants lacking the endospermderived embryo-sheath in Arabidopsis. Loss of the sheath impedes cotyledon escape due to adhesion between the two tissues (41). Seedling establishment defects, including a failure to establish autotrophic growth, correlate with cotyledon "trapping" within the seed coat, and, unlike the phenotypes associated with the removal of the endosperm prior to germination, can be alleviated by the addition of sucrose to the culture medium during germination. These finding nonetheless highlight the importance of timely cotyledon release from surrounding endosperm cells in the establishment of young seedlings. 


\section{SUMMARY POINTS}

1. The communication pathways between the embryo and endosperm change dynamically as seeds develop and differ between different angiosperm species, with particularly variable roles for the suspensor. The early symplastic isolation of the embryo proper from the endosperm seems to be a universal feature.

2. The embryo-endosperm interface is the site of energy import into the embryo. Embryo-derived signals are important for resource release from the endosperm both post germination and potentially during development

3. The presence of an intact apoplastic barrier (cuticle) on the surface of the embryos of epigeal species requires a peptide mediated dialogue between the embryo and endosperm. This barrier plays protective roles both during seed development and at germination, but potentially also restricts both communication and nutrient absorption.

4. Cellularization of the endosperm appears to play a critical role in ensuring the nutrition of the developing embryo. Even in species with an endosperm that remains essentially "uncellularized", bridges, formed by endosperm-derived cell walls, connect the embryo to the maternal apoplast.

5. The invasive growth of the embryo into the endosperm, both during development and during germination, is associated with cell death in this tissue and further remodeling of the embryoendosperm interface, which may facilitate nutrient uptake.

6. The importance of embryo-endosperm interactions during seed development highlights the importance of distinguishing these two very distinct tissues, when trying to understand fundamental aspects of seed biology. 


\section{FUTURE ISSUES}

1. What is the precise composition and structure of the apoplastic interface between the embryo and the endosperm, and what are the molecular mechanisms underlying its modification during seed development and germination?

2. Peptides and hormones are known to be involved in embryo-endosperm communication. Are other chemical signals also implicated?

3. Can the biophysical properties of the apoplastic interfaces between the embryo and the endosperm at different stages of seed development, particularly with regard to the diffusion of nutrients and signals, be accurately measured?

4. How are forces exerted by the embryo on the endosperm perceived and interpreted?

5. To what extent are molecular mechanisms identified in Arabidopsis and other model species conserved in crops, and do they represent targets for long-term crop improvement strategies.

Table 1: Proteins referred to in this review

\begin{tabular}{|c|c|c|c|}
\hline Protein and identifier & Protein type & Page & References \\
\hline $\begin{array}{l}\text { AAD1/5 (ACYL-ACYL CARRIER } \\
\text { PROTEIN DESATURASE1/5) } \\
\text { (AT5G16240/AT3G02630) }\end{array}$ & $\Delta 9$ stearoyl-ACP desaturase & & $(90)$ \\
\hline $\begin{array}{l}\text { ACR4 (ARABIDOPSIS CRINKLY 4) } \\
\text { (AT3G59420) }\end{array}$ & receptor-like kinase & & $(123,138,168)$ \\
\hline $\begin{array}{l}\text { AGL62 (AGAMOUS-LIKE 62) } \\
\text { (AT5G60440) }\end{array}$ & $\begin{array}{l}\text { Type I MADS domain } \\
\text { transcription factor }\end{array}$ & & $(73,86)$ \\
\hline $\begin{array}{l}\text { ALE1 (ABNORMAL LEAF-SHAPE 1) } \\
\text { (AT1G62340) }\end{array}$ & subtilisin-like serine protease & & $(44,156)$ \\
\hline $\begin{array}{l}\text { ALE2 (ABNORMAL LEAF-SHAPE 2) } \\
\text { (AT2G20300) }\end{array}$ & receptor-like kinase & & $(157)$ \\
\hline $\begin{array}{l}\text { ATML1 (MERISTEM LAYER 1) } \\
\text { (AT4G21750) }\end{array}$ & homeodomain protein & & $(123,138)$ \\
\hline $\begin{array}{l}\text { (At)CAT6 (CATIONIC AMINO ACID } \\
\text { TRANSPORTER 6) (AT5G04770) }\end{array}$ & cationic amino acid transporter & & $(70)$ \\
\hline $\begin{array}{l}\text { CIF1/2 (CASPARIAN STRIP INTEGRITY } \\
\text { FACTOR 1/2) (AT2G16385/AT4G34600) }\end{array}$ & $\begin{array}{l}\text { Precursor of a sulfated CIF-like } \\
\text { peptide }\end{array}$ & & $(40,126)$ \\
\hline $\begin{array}{l}\text { (At)DEK1(DEFECTIVE KERNEL 1) } \\
\text { (AT1G55350) }\end{array}$ & $\begin{array}{l}\text { plant specific CALPAIN protease } \\
\text { (phytocalpain) }\end{array}$ & & $(112)$ \\
\hline $\begin{array}{l}\text { ESF1.1/2/3 (EMBRYO SURROUNDING } \\
\text { FACTOR 1. 1/2/3) (AT1G10747/ } \\
\text { AT1G10745/AT1G10717) }\end{array}$ & $\begin{array}{l}\text { Maternally expressed gene } \\
\text { (MEG) family cysteine rich } \\
\text { peptide precursor }\end{array}$ & & (30) \\
\hline (At)EXP2 (EXPANSIN A2) (AT5G05290) & EXPANSIN (cell wall protein) & & $(23,139,178)$ \\
\hline
\end{tabular}




\begin{tabular}{|c|c|c|}
\hline $\begin{array}{l}\text { FAB2 (FATTY ACID BIOSYNTHESIS 2) } \\
\text { (AT2G43710) }\end{array}$ & stearoyl-ACP desaturase & (90) \\
\hline $\begin{array}{l}\text { GSO1/2 (GASSHO1/2) } \\
\text { (AT4G20140/AT5G44700) }\end{array}$ & leucine rich repeat (LRR) kinase & $(44,162,174)$ \\
\hline IKU1 (HAIKU1) (AT2G35230) & VQ-motif containing protein & $(167)$ \\
\hline IKU2 (HAIKU2) (AT3G19700) & $\begin{array}{l}\text { leucine rich repeat (LRR) } \\
\text { receptor-like kinase }\end{array}$ & (109) \\
\hline $\begin{array}{l}\text { HDG11/12 (HOMEODOMAIN } \\
\text { GLABROUS 11/12) (AT1G73360/ } \\
\text { AT1G17920) }\end{array}$ & homeodomain protein & (163) \\
\hline $\begin{array}{l}\text { ICE1 (INDUCER OF CBF EXPRESSION } \\
1 \text { (AT3G26744 }\end{array}$ & $\begin{array}{l}\text { MYC-like bHLH transcription } \\
\text { factor }\end{array}$ & $(28,38,85)$ \\
\hline KRS (KERBEROS) (AT1G50650) & $\begin{array}{l}\text { STIG1 family cysteine-rich } \\
\text { peptide precursor }\end{array}$ & $(41,122)$ \\
\hline KOD (KISS OF DEATH) (locus unknown) & Small cytoplasmic peptide & (14) \\
\hline MINI3 (MINISEED 3) (AT1G55600) & WRKY DNA-binding protein & (109) \\
\hline $\begin{array}{l}\text { PDF2 (PROTODERMAL FACTOR 2) } \\
\text { (AT4G04890) }\end{array}$ & homeodomain protein & (138) \\
\hline RGL2 (RGA-Like 2) (AT3G03450) & GRAS family transcription factor & $(106)$ \\
\hline $\begin{array}{l}\text { SUC5 (SUCROSE-PROTON } \\
\text { SYMPORTER 5) (AT1G71890) }\end{array}$ & sucrose-proton symporter & (7) \\
\hline $\begin{array}{l}\text { SSP (SHORT SUSPENSOR) } \\
\text { (AT2G17090) }\end{array}$ & RLCK II family kinase & (8) \\
\hline $\begin{array}{l}\text { SWEET11/15 (AT3G48740/ } \\
\text { AT5G13170) }\end{array}$ & $\begin{array}{l}\text { sucrose efflux transporter } \\
\text { proteins }\end{array}$ & (26) \\
\hline $\begin{array}{l}\text { TPST (TYROSYLPROTEIN } \\
\text { SULFOTRANSFERASE) (AT1G08030) }\end{array}$ & tyrosylprotein sulfotransferase & $(34,40,44)$ \\
\hline TWS1 (TWISTED SEED 1) (AT5G01075) & $\begin{array}{l}\text { Precursor of a sulfated CIF-like } \\
\text { peptide }\end{array}$ & $(44,57)$ \\
\hline $\begin{array}{l}\text { UMAMIT25/28 (USUALLY MULTIPLE } \\
\text { ACIDS MOVE IN AND OUT } \\
\text { TRANSPORTERS 25/28) } \\
\text { ( AT1G09380/ AT1G01070) }\end{array}$ & $\begin{array}{l}\text { nodulin MtN21-like transporter } \\
\text { family protein }\end{array}$ & (124) \\
\hline WRI1 (WRINKLED 1) (AT3G54320) & $\begin{array}{l}\text { AP2/ERWEBP transcription } \\
\text { factor }\end{array}$ & $(90,161)$ \\
\hline $\begin{array}{l}\text { YUC 1/4/10/11 (YUCCA 1/4/10/11) } \\
\text { (AT4G32540/AT5G11320/ } \\
\text { AT1G48910/ AT1G21430) }\end{array}$ & flavin monooxygenase & $(6,53,134)$ \\
\hline (Os)YUC11 (YUCCA11)(Os12g08780) & flavin monooxygenase & (176) \\
\hline 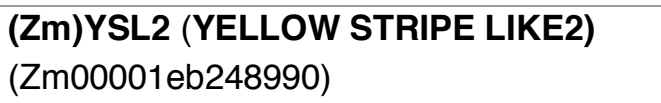 & $\begin{array}{l}\text { metal-nicotianamine (NA) } \\
\text { transporter family protein }\end{array}$ & $(184)$ \\
\hline $\begin{array}{l}\text { ZOU/RGE1 (ZHOUPI/ RETARDED } \\
\text { GROWTH OF EMBRYO 1) (AT1G49770) }\end{array}$ & $\begin{array}{l}\text { basic helix loop helix family } \\
\text { transcription factor }\end{array}$ & $(93,180)$ \\
\hline 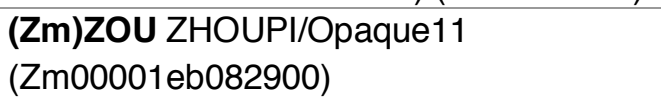 & $\begin{array}{l}\text { basic helix loop helix family } \\
\text { transcription factor }\end{array}$ & $(51,66)$ \\
\hline
\end{tabular}

Acknowledgments: We thank Jekaterina Truskina for her critical comments. Nicolas M. Doll is funded by an EMBO fellowship (ALTF 90-2020) and by the Bettencourt-Schueller foundation. 
1. Aguirre M, Kiegle E, Leo G, Ezquer I. 2018. Carbohydrate reserves and seed development: an overview. Plant Reprod. 31(3):263-90

2. Allorent G, Osorio S, Vu JL, Falconet D, Jouhet J, et al. 2015. Adjustments of embryonic photosynthetic activity modulate seed fitness in Arabidopsis thaliana. New Phytol. 205(2):707-19

3. Babu Y, Musielak T, Henschen A, Bayer M. 2013. Suspensor length determines developmental progression of the embryo in Arabidopsis. Plant Physiol. 162(3):1448-58

4. Barber KG. 1909. Comparative Histology of Fruits and Seeds of Certain Species of Cucurbitaceae. Botanical Gazette. 47(4):263-310

5. Baroux C, Spillane C, Grossniklaus U. 2002. Evolutionary origins of the endosperm in flowering plants. Genome Biology. 3(9):reviews1026.1

6. Batista RA, Figueiredo DD, Santos-González J, Köhler C. 2019. Auxin regulates endosperm cellularization in Arabidopsis. Genes Dev. 33(7-8):466-76

7. Baud S, Wuillème S, Lemoine R, Kronenberger J, Caboche M, et al. 2005. The AtSUC5 sucrose transporter specifically expressed in the endosperm is involved in early seed development in Arabidopsis. Plant J. 43(6):824-36

8. Bayer M, Nawy T, Giglione C, Galli M, Meinnel T, Lukowitz W. 2009. Paternal control of embryonic patterning in Arabidopsis thaliana. Science. 323(5920):1485-88

9. Berhin A, de Bellis D, Franke RB, Buono RA, Nowack MK, Nawrath C. 2019. The Root Cap Cuticle: A Cell Wall Structure for Seedling Establishment and Lateral Root Formation. Cell. 176(6):1367-1378.e8

10. Besnard J, Zhao C, Avice J-C, Vitha S, Hyodo A, et al. 2018. Arabidopsis UMAMIT24 and 25 are amino acid exporters involved in seed loading. Journal of Experimental Botany. 69(21):5221-32

11. Bethke null, Lonsdale null, Fath null, Jones null. 1999. Hormonally regulated programmed cell death in barley aleurone cells. Plant Cell. 11(6):1033-46

12. Bethke PC, Libourel IGL, Aoyama N, Chung Y-Y, Still DW, Jones RL. 2007. The Arabidopsis Aleurone Layer Responds to Nitric Oxide, Gibberellin, and Abscisic Acid and Is Sufficient and Necessary for Seed Dormancy. Plant Physiol. 143(3):1173-88

13. Bewley JD. 1997. Seed Germination and Dormancy. Plant Cell. 9(7):1055-66 
14. Blanvillain R, Young B, Cai Y, Hecht V, Varoquaux F, et al. 2011. The Arabidopsis peptide kiss of death is an inducer of programmed cell death. EMBO J. 30(6):1173-83

15. Borisjuk L, Rolletschek H. 2009. The oxygen status of the developing seed. New Phytol. 182(1):17-30

16. Borisjuk L, Rolletschek H, Wobus U, Weber H. 2003. Differentiation of legume cotyledons as related to metabolic gradients and assimilate transport into seeds. Journal of Experimental Botany. 54(382):503-12

17. Borisjuk L, Walenta S, Rolletschek H, Mueller-Klieser W, Wobus U, Weber H. 2002. Spatial analysis of plant metabolism: Sucrose imaging within Vicia faba cotyledons reveals specific developmental patterns. The Plant Journal. 29(4):521-30

18. Borisjuk L, Wang TL, Rolletschek H, Wobus U, Weber H. 2002. A pea seed mutant affected in the differentiation of the embryonic epidermis is impaired in embryo growth and seed maturation. Development. 129(7):1595-1607

19. Briggs CL. 1993. Endosperm Development in Solanum nigrum L. Formation of the Zone of Separation and Secretion. Annals of Botany. 72(4):303-13

20. Briggs CL. 1996. An Ultrastructural Study of The Embryo/Endosperm Interface in the Developing Seeds of Solanum nigrum L. Zygote to Mid Torpedo Stage. Annals of Botany. 78(3):295-304

21. Brown RC, Lemmon BE, Nguyen H, Olsen O-A. 1999. Development of endosperm in Arabidopsis thaliana. Sex Plant Reprod. 12(1):32-42

22. Cannon MC, Terneus $K$, Hall Q, Tan L, Wang $\mathrm{Y}$, et al. 2008. Self-assembly of the plant cell wall requires an extensin scaffold. PNAS. 105(6):2226-31

23. Carrera-Castaño G, Calleja-Cabrera J, Pernas M, Gómez L, Oñate-Sánchez L. 2020. An Updated Overview on the Regulation of Seed Germination. Plants. 9(6):703

24. Chahtane H, Kim W, Lopez-Molina L. 2017. Primary seed dormancy: a temporally multilayered riddle waiting to be unlocked. J Exp Bot. 68(4):857-69

25. Chen J, Lausser A, Dresselhaus T. 2014. Hormonal responses during early embryogenesis in maize. Biochem Soc Trans. 42(2):325-31 
26. Chen L-Q, Lin IW, Qu X-Q, Sosso D, McFarlane HE, et al. 2015. A Cascade of Sequentially Expressed Sucrose Transporters in the Seed Coat and Endosperm Provides Nutrition for the Arabidopsis Embryo. The Plant Cell. 27(3):607-19

27. Chen M, Lin J-Y, Wu X, Apuya NR, Henry KF, et al. 2021. Comparative analysis of embryo proper and suspensor transcriptomes in plant embryos with different morphologies. Proc Natl Acad Sci U SA. 118(6):

28. Chinnusamy V, Ohta M, Kanrar S, Lee B-H, Hong X, et al. 2003. ICE1: a regulator of cold-induced transcriptome and freezing tolerance in Arabidopsis. Genes Dev. 17(8):1043-54

29. Corona-Carrillo Jl, Flores-Ponce M, Chávez-Nájera G, Díaz-Pontones DM. 2014. Peroxidase activity in scutella of maize in association with anatomical changes during germination and grain storage. Springerplus. 3:399

30. Costa LM, Marshall E, Tesfaye M, Silverstein KAT, Mori M, et al. 2014. Central cell-derived peptides regulate early embryo patterning in flowering plants. Science. 344(6180):168-72

31. Creff A, Brocard L, Joubès J, Taconnat L, Doll NM, et al. 2019. A stress-response-related intercompartmental signalling pathway regulates embryonic cuticle integrity in Arabidopsis. PLOS Genetics. 15(4):e1007847

32. Cubría-Radío M, Nowack MK. 2019. Transcriptional networks orchestrating programmed cell death during plant development. Curr Top Dev Biol. 131:161-84

33. David LC, Berquin P, Kanno Y, Seo M, Daniel-Vedele F, Ferrario-Méry S. 2016. N availability modulates the role of NPF3.1, a gibberellin transporter, in GA-mediated phenotypes in Arabidopsis. Planta. 244(6):1315-28

34. De Giorgi J, Fuchs C, Iwasaki M, Kim W, Piskurewicz U, et al. The mature endosperm governs early seedling development: a focus on cuticle formation. In press

35. De Jong TJ, Van Dijk H, Klinkhamer PGL. 2005. Hamilton's rule, imprinting and parent-offspring conflict over seed mass in partially selfing plants. J. Evol. Biol. 18(3):676-82 
36. Dekkers BJW, Pearce S, van Bolderen-Veldkamp RP, Marshall A, Widera P, et al. 2013.

Transcriptional dynamics of two seed compartments with opposing roles in Arabidopsis seed germination. Plant Physiol. 163(1):205-15

37. Delude C, Moussu S, Joubès J, Ingram G, Domergue F. 2016. Plant Surface Lipids and Epidermis Development. Subcell. Biochem. 86:287-313

38. Denay G, Creff A, Moussu S, Wagnon P, Thévenin J, et al. 2014. Endosperm breakdown in Arabidopsis requires heterodimers of the basic helix-loop-helix proteins ZHOUPI and INDUCER OF CBP EXPRESSION 1. Development. 141(6):1222-27

39. Diboll AG. 1968. Fine Structural Development of the Megagametophyte of Zea mays Following Fertilization. American Journal of Botany. 55(7):797-806

40. Doblas VG, Smakowska-Luzan E, Fujita S, Alassimone J, Barberon M, et al. 2017. Root diffusion barrier control by a vasculature-derived peptide binding to the SGN3 receptor. Science. $355(6322): 280-84$

41. Doll NM, Bovio S, Gaiti A, Marsollier A-C, Chamot S, et al. 2020. The Endosperm-Derived Embryo Sheath Is an Anti-adhesive Structure that Facilitates Cotyledon Emergence during Germination in Arabidopsis. Curr Biol. 30(5):909-915.e4

42. Doll NM, Depège-Fargeix N, Rogowsky PM, Widiez T. 2017. Signaling in Early Maize Kernel Development. Mol Plant. 10(3):375-88

43. Doll NM, Just J, Brunaud V, Caïus J, Grimault A, et al. 2020. Transcriptomics at Maize Embryo/Endosperm Interfaces Identifies a Transcriptionally Distinct Endosperm Subdomain Adjacent to the Embryo Scutellum. The Plant Cell. 32(4):833-52

44. Doll NM, Royek S, Fujita S, Okuda S, Chamot S, et al. 2020. A two-way molecular dialogue between embryo and endosperm is required for seed development. Science. 367(6476):431-35

45. Doll NM, Royek S, Fujita S, Okuda S, Chamot S, et al. 2020. A two-way molecular dialogue between embryo and endosperm is required for seed development. Science. 367(6476):431-35

46. Dou M, Zhang Y, Yang S, Feng X. 2018. Identification of ZHOUPI Orthologs in Rice Involved in Endosperm Development and Cuticle Formation. Front. Plant Sci. 9: 
47. Dute RR, Peterson CM, Rushing AE. 1989. Ultrastructural Changes of the Egg Apparatus Associated with Fertilization and Proembryo Development of Soybean, Glycine max (Fabaceae). Annals of Botany. 64(2):123-35

48. Dutta S, Bradford KJ, Nevins DJ. 1994. Cell-Wall Autohydrolysis in Isolated Endosperms of Lettuce (Lactuca sativa L.). Plant Physiol. 104(2):623-28

49. Dutta S, Bradford KJ, Nevins DJ. 1997. Endo-[beta]-Mannanase Activity Present in Cell Wall Extracts of Lettuce Endosperm prior to Radicle Emergence. Plant Physiol. 113(1):155-61

50. Erdmann RM, Hoffmann A, Walter H-K, Wagenknecht H-A, Groß-Hardt R, Gehring M. 2017. Molecular movement in the Arabidopsis thaliana female gametophyte. Plant Reprod. 30(3):141-46

51. Feng F, Qi W, Lv Y, Yan S, Xu L, et al. 2018. OPAQUE11 Is a Central Hub of the Regulatory Network for Maize Endosperm Development and Nutrient Metabolism. Plant Cell. 30(2):375-96

52. Figueiredo DD, Batista RA, Roszak PJ, Hennig L, Köhler C. 2016. Auxin production in the endosperm drives seed coat development in Arabidopsis. Elife. 5:

53. Figueiredo DD, Batista RA, Roszak PJ, Köhler C. 2015. Auxin production couples endosperm development to fertilization. Nature Plants. 1(12):1-6

54. Figueiredo DD, Batista RA, Roszak PJ, Köhler C. 2015. Auxin production couples endosperm development to fertilization. Nat Plants. 1:15184

55. Figueiredo DD, Köhler C. 2018. Auxin: a molecular trigger of seed development. Genes Dev. 32(78):479-90

56. Finch-Savage WE, Leubner-Metzger G. 2006. Seed dormancy and the control of germination. New Phytol. 171(3):501-23

57. Fiume E, Guyon V, Remoué C, Magnani E, Miquel M, et al. 2016. TWS1, a Novel Small Protein, Regulates Various Aspects of Seed and Plant Development. Plant Physiol. 172(3):1732-45

58. Forestan C, Meda S, Varotto S. 2010. ZmPIN1-Mediated Auxin Transport Is Related to Cellular Differentiation during Maize Embryogenesis and Endosperm Development. Plant Physiology. 152(3):1373-90 
59. Forestan C, Varotto S. 2012. The Role of PIN Auxin Efflux Carriers in Polar Auxin Transport and Accumulation and Their Effect on Shaping Maize Development. Molecular Plant. 5(4):787-98

60. Fourquin C, Beauzamy L, Chamot S, Creff A, Goodrich J, et al. 2016. Mechanical stress mediated by both endosperm softening and embryo growth underlies endosperm elimination in Arabidopsis seeds. Development. 143(18):3300-3305

61. Friedman WE, Ryerson KC. 2009. Reconstructing the ancestral female gametophyte of angiosperms: Insights from Amborella and other ancient lineages of flowering plants. Am J Bot. 96(1):129-43

62. Friml J, Vieten A, Sauer M, Weijers D, Schwarz H, et al. 2003. Efflux-dependent auxin gradients establish the apical-basal axis of Arabidopsis. Nature. 426(6963):147-53

63. Gao Z, Daneva A, Salanenka Y, Van Durme M, Huysmans M, et al. 2018. KIRA1 and ORESARA1 terminate flower receptivity by promoting cell death in the stigma of Arabidopsis. Nature Plants. $4(6): 365-75$

64. Garcia D, Fitz Gerald JN, Berger F. 2005. Maternal control of integument cell elongation and zygotic control of endosperm growth are coordinated to determine seed size in Arabidopsis. Plant Cell. 17(1):52-60

65. Gehring M, Satyaki PR. 2017. Endosperm and Imprinting, Inextricably Linked. Plant Physiol. 173(1):143-54

66. Grimault A, Gendrot G, Chamot S, Widiez T, Rabillé H, et al. 2015. ZmZHOUPI, an endosperm-specific basic helix-loop-helix transcription factor involved in maize seed development. Plant J. 84(3):574-86

67. Grossniklaus U, Spillane C, Page DR, Köhler C. 2001. Genomic imprinting and seed development: endosperm formation with and without sex. Current Opinion in Plant Biology. 4(1):21-27

68. Grossniklaus U, Vielle-Calzada JP, Hoeppner MA, Gagliano WB. 1998. Maternal control of embryogenesis by MEDEA, a polycomb group gene in Arabidopsis. Science. 280(5362):446-50

69. Haig D, Westoby M. 1989. Parent-Specific Gene Expression and the Triploid Endosperm. The American Naturalist. 134(1):147-55

70. Hammes UZ, Nielsen E, Honaas LA, Taylor CG, Schachtman DP. 2006. AtCAT6, a sink-tissue-localized transporter for essential amino acids in Arabidopsis. Plant J. 48(3):414-26 
71. Han Y-Z, Huang B-Q, Zee S-Y, Yuan M. 2000. Symplastic communication between the central cell and the egg apparatus cells in the embryo sac of Torenia fournieri Lind. before and during fertilization. Planta. 211(1):158-62

72. Hauvermale AL, Steber CM. 2020. GA signaling is essential for the embryo-to-seedling transition during Arabidopsis seed germination, a ghost story. Plant Signaling \& Behavior. 15(1):1705028

73. Hehenberger E, Kradolfer D, Köhler C. 2012. Endosperm cellularization defines an important developmental transition for embryo development. Development. 139(11):2031-39

74. Hsieh T-F, Shin J, Uzawa R, Silva P, Cohen S, et al. 2011. Regulation of imprinted gene expression in Arabidopsis endosperm. PNAS. 108(5):1755-62

75. Huang B-Q, Russell SD. 1992. Female Germ Unit: Organization, Isolation, and Function. In International Review of Cytology, ed SD Russell, C Dumas. 140:233-93. Academic Press

76. Ibarra CA, Feng X, Schoft VK, Hsieh T-F, Uzawa R, et al. 2012. Active DNA demethylation in plant companion cells reinforces transposon methylation in gametes. Science. 337(6100):1360-64

77. Iglesias-Fernández R, Barrero-Sicilia C, Carrillo-Barral N, Oñate-Sánchez L, Carbonero P. 2013. Arabidopsis thaliana bZIP44: a transcription factor affecting seed germination and expression of the mannanase-encoding gene AtMAN7. Plant J. 74(5):767-80

78. Iglesias-Fernández R, Rodríguez-Gacio MC, Barrero-Sicilia C, Carbonero P, Matilla A. 2011. Three endo- $\beta$-mannanase genes expressed in the micropylar endosperm and in the radicle influence germination of Arabidopsis thaliana seeds. Planta. 233(1):25-36

79. Ingensiep HW. 2004. The History of the Plant Embryo. Terminology and Visualization from Ancient until Modern Times. History and Philosophy of the Life Sciences. 26(3/4):309-31

80. Ingram G, Nawrath C. 2017. The roles of the cuticle in plant development: organ adhesions and beyond. J. Exp. Bot. 68(19):5307-21

81. Iwasaki M, Penfield S, Lopez-Molina L. in press. Parental and environmental control of seed dormancy in Arabidopsis thaliana. Annual Review of Plant Biology

82. Jane W-N. 1997. Ultrastructure of the Maturing Egg Apparatus in Arundo formosana Hack. (Poaceae). International Journal of Plant Sciences. 158(6):713-26 
83. Javelle M, Vernoud V, Rogowsky PM, Ingram GC. 2011. Epidermis: the formation and functions of a fundamental plant tissue. New Phytol. 189(1):17-39

84. Johansson M, Walles B. 1993. Functional Anatomy of the Ovule in Broad Bean, Vicia faba L. II. Ultrastructural Development up to Early Embryogenesis. International Journal of Plant Sciences. 154(4):535-49

85. Kanaoka MM, Pillitteri $\sqcup$, Fujii $H$, Yoshida $Y$, Bogenschutz NL, et al. 2008. SCREAM/ICE1 and SCREAM2 specify three cell-state transitional steps leading to arabidopsis stomatal differentiation. Plant Cell. 20(7):1775-85

86. Kang I-H, Steffen JG, Portereiko MF, Lloyd A, Drews GN. 2008. The AGL62 MADS domain protein regulates cellularization during endosperm development in Arabidopsis. Plant Cell. 20(3):635-47

87. Kang J, Yim S, Choi H, Kim A, Lee KP, et al. 2015. Abscisic acid transporters cooperate to control seed germination. Nat Commun. 6:8113

88. Kanno Y, Oikawa T, Chiba Y, Ishimaru Y, Shimizu T, et al. 2016. AtSWEET13 and AtSWEET14 regulate gibberellin-mediated physiological processes. Nat Commun. 7:

89. Kawashima T, Goldberg RB. 2010. The suspensor: not just suspending the embryo. Trends Plant Sci. 15(1):23-30

90. Kazaz S, Barthole G, Domergue F, Ettaki H, To A, et al. 2020. Differential Activation of Partially Redundant $\Delta 9$ Stearoyl-ACP Desaturase Genes Is Critical for Omega-9 Monounsaturated Fatty Acid Biosynthesis During Seed Development in Arabidopsis. Plant Cell. 32(11):3613-37

91. Kiyosue T, Ohad N, Yadegari R, Hannon M, Dinneny J, et al. 1999. Control of fertilizationindependent endosperm development by the MEDEA polycomb gene in Arabidopsis. Proc. Natl. Acad. Sci. U.S.A. 96(7):4186-91

92. Köhler C, Hennig L, Bouveret R, Gheyselinck J, Grossniklaus U, Gruissem W. 2003. Arabidopsis MSI1 is a component of the MEA/FIE Polycomb group complex and required for seed development. EMBO J. 22(18):4804-14 
93. Kondou Y, Nakazawa M, Kawashima M, Ichikawa T, Yoshizumi T, et al. 2008. RETARDED GROWTH OF EMBRYO1, a new basic helix-loop-helix protein, expresses in endosperm to control embryo growth. Plant Physiol. 147(4):1924-35

94. Kourmpetli S, Drea S. 2014. The fruit, the whole fruit, and everything about the fruit. J Exp Bot. 65(16):4491-4503

95. Kozieradzka-Kiszkurno M, Majcher D, Brzezicka E, Rojek J, Wróbel-Marek J, Kurczyńska E. 2020. Development of Embryo Suspensors for Five Genera of Crassulaceae with Special Emphasis on Plasmodesmata Distribution and Ultrastructure. Plants (Basel). 9(3):

96. Kozieradzka-Kiszkurno M, Płachno BJ. 2012. Are there symplastic connections between the endosperm and embryo in some angiosperms? - a lesson from the Crassulaceae family. Protoplasma. 249(4):1081-89

97. Kozieradzka-Kiszkurno M, Płachno BJ, Bohdanowicz J. 2012. New data about the suspensor of succulent angiosperms: Ultrastructure and cytochemical study of the embryo-suspensor of Sempervivum arachnoideum L. and Jovibarba sobolifera (Sims) Opiz. Protoplasma. 249(3):613-24

98. Kradolfer D, Hennig L, Köhler C. 2013. Increased maternal genome dosage bypasses the requirement of the FIS polycomb repressive complex 2 in Arabidopsis seed development. PLoS Genet. 9(1):e1003163

99. Kranz E, Wiegen P von, Lörz H. 1995. Early cytological events after induction of cell division in egg cells and zygote development following in vitro fertilization with angiosperm gametes. The Plant Journal. 8(1):9-23

100. La Rocca N, Manzotti PS, Cavaiuolo M, Barbante A, Dalla Vecchia F, et al. 2015. The maize fused leaves1 ( $\mathrm{fdl} 1$ ) gene controls organ separation in the embryo and seedling shoot and promotes coleoptile opening. J Exp Bot. 66(19):5753-67

101. Lafon Placette C. 2020. Endosperm genome dosage, hybrid seed failure, and parental imprinting: sexual selection as an alternative to parental conflict. Am J Bot. 107(1):17-19

102. Lafon-Placette C, Köhler C. 2016. Endosperm-based postzygotic hybridization barriers: developmental mechanisms and evolutionary drivers. Mol. Ecol. 25(11):2620-29 
103. Lamport DTA, Kieliszewski MJ, Chen Y, Cannon MC. 2011. Role of the Extensin Superfamily in Primary Cell Wall Architecture. Plant Physiology. 156(1):11-19

104. Lee B, Henderson DA, Zhu J-K. 2005. The Arabidopsis cold-responsive transcriptome and its regulation by ICE1. Plant Cell. 17(11):3155-75

105. Lee KJD, Dekkers BJW, Steinbrecher T, Walsh CT, Bacic A, et al. 2012. Distinct cell wall architectures in seed endosperms in representatives of the Brassicaceae and Solanaceae. Plant Physiol. 160(3):1551-66

106. Lee KP, Piskurewicz U, Turecková V, Strnad M, Lopez-Molina L. 2010. A seed coat bedding assay shows that RGL2-dependent release of abscisic acid by the endosperm controls embryo growth in Arabidopsis dormant seeds. Proc. NatI. Acad. Sci. U.S.A. 107(44):19108-13

107. Linkies A, Graeber K, Knight C, Leubner-Metzger G. 2010. The evolution of seeds. New Phytol. 186(4):817-31

108. Luo M, Bilodeau P, Dennis ES, Peacock WJ, Chaudhury A. 2000. Expression and parent-of-origin effects for FIS2, MEA, and FIE in the endosperm and embryo of developing Arabidopsis seeds. Proc. Natl. Acad. Sci. U.S.A. 97(19):10637-42

109. Luo M, Dennis ES, Berger F, Peacock WJ, Chaudhury A. 2005. MINISEED3 (MINI3), a WRKY family gene, and HAIKU2 (IKU2), a leucine-rich repeat (LRR) KINASE gene, are regulators of seed size in Arabidopsis. Proc. Natl. Acad. Sci. U.S.A. 102(48):17531-36

110. MacGregor DR, Zhang N, Iwasaki M, Chen M, Dave A, et al. 2019. ICE1 and ZOU determine the depth of primary seed dormancy in Arabidopsis independently of their role in endosperm development. Plant J. 98(2):277-90

111. Maheshwari P. 1950. An introduction to the embryology of angiosperms. New York,: McGraw-Hill,. 472 pp. 1st ed. ed.

112. Malivert A, Hamant O, Ingram G. 2018. The contribution of mechanosensing to epidermal cell fate specification. Curr. Opin. Genet. Dev. 51:52-58

113. Mansfield SG, Briarty LG. 1991. Early embryogenesis in Arabidopsis thaliana. II. The developing embryo. Canadian journal of botany = Journal canadien de botanique 
114. Marinos NG. 1970. Embryogenesis of the pea (Pisum sativum) I. The cytological environment of the developing embryo. Protoplasma. 70(3):261-79

115. Marsollier A-C, Ingram G. 2018. Getting physical: invasive growth events during plant development. Curr Opin Plant Biol. 46:8-17

116. Martínez-Andújar C, Pluskota WE, Bassel GW, Asahina M, Pupel P, et al. 2012. Mechanisms of hormonal regulation of endosperm cap-specific gene expression in tomato seeds. Plant J. 71(4):57586

117. Matilla AJ. 2019. Seed coat formation: its evolution and regulation. Seed Science Research. 29(4):215-26

118. Miray R, Kazaz S, To A, Baud S. 2021. Molecular Control of Oil Metabolism in the Endosperm of Seeds. Int J Mol Sci. 22(4):

119. Mogensen HL, Suthar HK. 1979. Ultrastructure of the Egg Apparatus of Nicotiana tabacum (Solanaceae) Before and After Fertilization. Botanical Gazette. 140(2):168-79

120. Morley-Smith ER, Pike MJ, Findlay K, Köckenberger W, Hill LM, et al. 2008. The Transport of Sugars to Developing Embryos Is Not via the Bulk Endosperm in Oilseed Rape Seeds. Plant Physiology. 147(4):2121-30

121. Moussu S, Doll NM, Chamot S, Brocard L, Creff A, et al. 2017. ZHOUPI and KERBEROS Mediate Embryo/Endosperm Separation by Promoting the Formation of an Extracuticular Sheath at the Embryo Surface. Plant Cell. 29(7):1642-56

122. Moussu S, Doll NM, Chamot S, Brocard L, Creff A, et al. 2017. ZHOUPI and KERBEROS Mediate Embryo/Endosperm Separation by Promoting the Formation of an Extracuticular Sheath at the Embryo Surface. Plant Cell. 29(7):1642-56

123. Moussu S, San-Bento R, Galletti R, Creff A, Farcot E, Ingram G. 2013. Embryonic cuticle establishment: the great (apoplastic) divide. Plant Signal Behav. 8(12):e27491

124. Müller B, Fastner A, Karmann J, Mansch V, Hoffmann T, et al. 2015. Amino Acid Export in Developing Arabidopsis Seeds Depends on UmamiT Facilitators. Current Biology. 25(23):3126-31 
125. Müller K, Tintelnot S, Leubner-Metzger G. 2006. Endosperm-limited Brassicaceae seed germination: abscisic acid inhibits embryo-induced endosperm weakening of Lepidium sativum (cress) and endosperm rupture of cress and Arabidopsis thaliana. Plant Cell Physiol. 47(7):864-77

126. Nakayama T, Shinohara H, Tanaka M, Baba K, Ogawa-Ohnishi M, Matsubayashi Y. 2017. A peptide hormone required for Casparian strip diffusion barrier formation in Arabidopsis roots. Science. 355(6322):284-86

127. Olsen O-A. 2004. Nuclear endosperm development in cereals and Arabidopsis thaliana. Plant Cell. 16 Suppl:S214-227

128. Opsahl-Ferstad HG, Le Deunff E, Dumas C, Rogowsky PM. 1997. ZmEsr, a novel endosperm-specific gene expressed in a restricted region around the maize embryo. Plant J. 12(1):235-46

129. Otegui M, Staehelin LA. 2000. Syncytial-type cell plates: a novel kind of cell plate involved in endosperm cellularization of Arabidopsis. Plant Cell. 12(6):933-47

130. Penfield S, Rylott EL, Gilday AD, Graham S, Larson TR, Graham IA. 2004. Reserve mobilization in the Arabidopsis endosperm fuels hypocotyl elongation in the dark, is independent of abscisic acid, and requires PHOSPHOENOLPYRUVATE CARBOXYKINASE1. Plant Cell. 16(10):2705-18

131. Pommerrenig B, Popko J, Heilmann M, Schulmeister S, Dietel K, et al. 2013. SUCROSE TRANSPORTER 5 supplies Arabidopsis embryos with biotin and affects triacylglycerol accumulation. Plant J. 73(3):392-404

132. Povilus RA, Diggle PK, Friedman WE. 2018. Evidence for parent-of-origin effects and interparental conflict in seeds of an ancient flowering plant lineage. Proc. Biol. Sci. 285(1872):

133. Raghavan V. 2003. Some reflections on double fertilization, from its discovery to the present. New Phytologist. 159(3):565-83

134. Robert HS, Park C, Guitérrez CL, Wójcikowska B, Pěnčík A, et al. 2018. Maternal auxin supply contributes to early embryo patterning in Arabidopsis. Nat Plants. 4(8):548-53

135. Rolletschek H, Weber H, Borisjuk L. 2003. Energy status and its control on embryogenesis of legumes. Embryo photosynthesis contributes to oxygen supply and is coupled to biosynthetic fluxes. Plant Physiol. 132(3):1196-1206 
136. Russell S. 1993. The Egg Cell: Development and Role in Fertilization and Early Embryogenesis. Plant Cell. 5(10):1349-59

137. Sabelli PA. 2012. Replicate and die for your own good: Endoreduplication and cell death in the cereal endosperm. Journal of Cereal Science. 56(1):9-20

138. San-Bento R, Farcot E, Galletti R, Creff A, Ingram G. 2014. Epidermal identity is maintained by cellcell communication via a universally active feedback loop in Arabidopsis thaliana. Plant J. 77(1):4658

139. Sánchez-Montesino R, Bouza-Morcillo L, Marquez J, Ghita M, Duran-Nebreda S, et al. 2019. A Regulatory Module Controlling GA-Mediated Endosperm Cell Expansion Is Critical for Seed Germination in Arabidopsis. Molecular Plant. 12(1):71-85

140. Sangduen N (Dep of A, Kreitner GL, Sorensen EL. 1983. Light and electron microscopy of embryo development in perennial and annual Medicago species. Canadian Journal of Botany (Canada)

141. Satyaki PRV, Gehring M. 2019. Paternally Acting Canonical RNA-Directed DNA Methylation Pathway Genes Sensitize Arabidopsis Endosperm to Paternal Genome Dosage. Plant Cell. 31(7):1563-78

142. Schel JHN, Lammeren AAM van, Kieft H. 1985. Ultrastructural analysis of embryo-endosperm interactions in developing maize seeds (Zea mays L.)

143. Scheler C, Weitbrecht K, Pearce SP, Hampstead A, Büttner-Mainik A, et al. 2015. Promotion of testa rupture during garden cress germination involves seed compartment-specific expression and activity of pectin methylesterases. Plant Physiol. 167(1):200-215

144. Schmid M, Simpson D, Gietl C. 1999. Programmed cell death in castor bean endosperm is associated with the accumulation and release of a cysteine endopeptidase from ricinosomes. PNAS. 96(24):14159-64

145. Schulz P, Jensen WA. 1971. Capsella Embryogenesis: the Chalazal Proliferating Tissue. Journal of Cell Science. 8(1):201-27

146. Sechet J, Frey A, Effroy-Cuzzi D, Berger A, Perreau F, et al. 2016. Xyloglucan Metabolism Differentially Impacts the Cell Wall Characteristics of the Endosperm and Embryo during Arabidopsis Seed Germination. Plant Physiol. 170(3):1367-80 
147. Sela A, Piskurewicz U, Megies C, Mène-Saffrané L, Finazzi G, Lopez-Molina L. 2020. Embryonic Photosynthesis Affects Post-Germination Plant Growth. Plant Physiology. 182(4):2166-81

148. Shigeyama T, Watanabe A, Tokuchi K, Toh S, Sakurai N, et al. 2016. $\alpha$-Xylosidase plays essential roles in xyloglucan remodelling, maintenance of cell wall integrity, and seed germination in Arabidopsis thaliana. J Exp Bot. 67(19):5615-29

149. Sørensen MB, Mayer U, Lukowitz W, Robert H, Chambrier P, et al. 2002. Cellularisation in the endosperm of Arabidopsis thaliana is coupled to mitosis and shares multiple components with cytokinesis. Development. 129(24):5567-76

150. Stadler R, Lauterbach C, Sauer N. 2005. Cell-to-Cell Movement of Green Fluorescent Protein Reveals Post-Phloem Transport in the Outer Integument and Identifies Symplastic Domains in Arabidopsis Seeds and Embryos. Plant Physiology. 139(2):701-12

151. Steffen JG, Kang I-H, Portereiko MF, Lloyd A, Drews GN. 2008. AGL61 Interacts with AGL80 and Is Required for Central Cell Development in Arabidopsis. Plant Physiology. 148(1):259-68

152. Steinbrecher T, Leubner-Metzger G. 2017. The biomechanics of seed germination. J. Exp. Bot. 68(4):765-83

153. Stępiński D, Kwiatkowska M, Wojtczak A, Domínguez E, Heredia A, Popłońska K. 2017. Cutinsomes as building-blocks of Arabidopsis thaliana embryo cuticle. Physiologia Plantarum. 161(4):560-67

154. Szczuka E, Szczuka A. 2003. Cuticle fluorescence during embryogenesis of Arabidopsis thaliana [L.] Heynh. Acta Biologica Cracoviensia. Series Botanica. 45(1):

155. Tal I, Zhang Y, Jørgensen ME, Pisanty O, Barbosa ICR, et al. 2016. The Arabidopsis NPF3 protein is a GA transporter. Nat Commun. 7:11486

156. Tanaka H, Onouchi H, Kondo M, Hara-Nishimura I, Nishimura M, et al. 2001. A subtilisin-like serine protease is required for epidermal surface formation in Arabidopsis embryos and juvenile plants. Development. 128(23):4681-89

157. Tanaka H, Watanabe M, Sasabe M, Hiroe T, Tanaka T, et al. 2007. Novel receptor-like kinase ALE2 controls shoot development by specifying epidermis in Arabidopsis. Development. 134(9):1643-52 
158. Tegeder M, Masclaux-Daubresse C. 2018. Source and sink mechanisms of nitrogen transport and use. New Phytol. 217(1):35-53

159. Tegeder M, Offler CE, Frommer WB, Patrick JW. 2000. Amino Acid Transporters Are Localized to Transfer Cells of Developing Pea Seeds. Plant Physiol. 122(2):319-26

160. Tekleyohans DG, Mao Y, Kägi C, Stierhof Y-D, Groß-Hardt R. 2017. Polyspermy barriers: a plant perspective. Curr Opin Plant Biol. 35:131-37

161. Troncoso-Ponce MA, Barthole G, Tremblais G, To A, Miquel M, et al. 2016. Transcriptional Activation of Two Delta-9 Palmitoyl-ACP Desaturase Genes by MYB115 and MYB118 Is Critical for Biosynthesis of Omega-7 Monounsaturated Fatty Acids in the Endosperm of Arabidopsis Seeds. Plant Cell. 28(10):2666-82

162. Tsuwamoto R, Fukuoka H, Takahata Y. 2008. GASSHO1 and GASSHO2 encoding a putative leucinerich repeat transmembrane-type receptor kinase are essential for the normal development of the epidermal surface in Arabidopsis embryos. Plant J. 54(1):30-42

163. Ueda M, Aichinger E, Gong W, Groot E, Verstraeten I, et al. 2017. Transcriptional integration of paternal and maternal factors in the Arabidopsis zygote. Genes Dev. 31(6):617-27

164. Van Lammeren AAM. 1987. Embryogenesis in Zea mays L.: A structural approach to maize caryopsis development in vivo and in vitro. PhD Thesis (Wageningen, The Netherlands: Wageningen University)

165. Vaughan JG, Whitehouse JM. 1971. Seed structure and the taxonomy of the Cruciferae. Botanical Journal of the Linnean Society. 64(4):383-409

166. Völz R, Lyncker L von, Baumann N, Dresselhaus T, Sprunck S, Groß-Hardt R. 2012. LACHESISdependent egg-cell signaling regulates the development of female gametophytic cells. Development. 139(3):498-502

167. Wang A, Garcia D, Zhang H, Feng K, Chaudhury A, et al. 2010. The VQ motif protein IKU1 regulates endosperm growth and seed size in Arabidopsis. Plant J. 63(4):670-79 
168. Watanabe M, Tanaka H, Watanabe D, Machida C, Machida Y. 2004. The ACR4 receptor-like kinase is required for surface formation of epidermis-related tissues in Arabidopsis thaliana. Plant J. 39(3):298-308

169. Waters A, Creff A, Goodrich J, Ingram G. 2013. "What we've got here is failure to communicate": zou mutants and endosperm cell death in seed development. Plant Signal Behav. 8(6):e24368

170. Weber H, Borisjuk L, Heim U, Sauer N, Wobus U. 1997. A role for sugar transporters during seed development: molecular characterization of a hexose and a sucrose carrier in fava bean seeds. Plant Cell. 9(6):895-908

171. Williams EG, Knox RB, Kaul V, Rouse JL. 1984. Post-pollination callose development in ovules of Rhododendron and Ledum (Ericaceae): zygote special wall. J Cell Sci. 69:127-35

172. Wróbel-Marek J, Kurczyńska E, Płachno BJ, Kozieradzka-Kiszkurno M. 2017. Identification of symplasmic domains in the embryo and seed of Sedum acre L. (Crassulaceae). Planta. 245(3):491505

173. Wu J-J, Peng X-B, Li W-W, He R, Xin H-P, Sun M-X. 2012. Mitochondrial GCD1 dysfunction reveals reciprocal cell-to-cell signaling during the maturation of Arabidopsis female gametes. Dev Cell. 23(5):1043-58

174. Xing Q, Creff A, Waters A, Tanaka H, Goodrich J, Ingram GC. 2013. ZHOUPI controls embryonic cuticle formation via a signalling pathway involving the subtilisin protease ABNORMAL LEAF-SHAPE1 and the receptor kinases GASSHO1 and GASSHO2. Development. 140(4):770-79

175. Xiong H, Wang W, Sun M-X. 2021. Endosperm development is an autonomously programmed process independent of embryogenesis. Plant Cell

176. Xu X, E Z, Zhang D, Yun Q, Zhou Y, et al. 2021. OsYUC11-mediated auxin biosynthesis is essential for endosperm development of rice. Plant Physiol. 185(3):934-50

177. Yamauchi Y, Ogawa M, Kuwahara A, Hanada A, Kamiya Y, Yamaguchi S. 2004. Activation of gibberellin biosynthesis and response pathways by low temperature during imbibition of Arabidopsis thaliana seeds. Plant Cell. 16(2):367-78 
178. Yan A, Wu M, Yan L, Hu R, Ali I, Gan Y. 2014. AtEXP2 Is Involved in Seed Germination and Abiotic Stress Response in Arabidopsis. PLOS ONE. 9(1):e85208

179. Yan D, Duermeyer L, Leoveanu C, Nambara E. 2014. The Functions of the Endosperm During Seed Germination. Plant and Cell Physiology. 55(9):1521-33

180. Yang S, Johnston N, Talideh E, Mitchell S, Jeffree C, et al. 2008. The endosperm-specific ZHOUPI gene of Arabidopsis thaliana regulates endosperm breakdown and embryonic epidermal development. Development. 135(21):3501-9

181. Yeats TH, Rose JKC. 2013. The formation and function of plant cuticles. Plant Physiol. 163(1):5-20

182. Yeung E, Meinke D. 1993. Embryogenesis in Angiosperms: Development of the Suspensor. Plant Cell. 5(10):1371-81

183. Yeung EC. 1980. Embryogeny of Phaseolus: the Role of the Suspensor. Zeitschrift für Pflanzenphysiologie. 96(1):17-28

184. Zang J, Huo Y, Liu J, Zhang H, Liu J, Chen H. 2020. Maize YSL2 is required for iron distribution and development in kernels. J Exp Bot. 71(19):5896-5910

185. Zhang Y, Chen B, Xu Z, Shi Z, Chen S, et al. 2014. Involvement of reactive oxygen species in endosperm cap weakening and embryo elongation growth during lettuce seed germination. J Exp Bot. 65(12):3189-3200 